\title{
Catecholaminergic C3 Neurons Are Sympathoexcitatory and Involved in Glucose Homeostasis
}

\author{
Clément Menuet, ${ }^{1}$ Charles P. Sevigny, ${ }^{1}$ Angela A. Connelly, ${ }^{1}$ Jaspreet K. Bassi, ${ }^{1}{ }^{\circ}$ Nikola Jancovski, ${ }^{1}$ David A. Williams, ${ }^{1}$ \\ Colin R. Anderson, ${ }^{2}$ Ida J. Llewellyn-Smith, ${ }^{3,4}$ Angelina Y. Fong, ${ }^{1}$ and ${ }^{\circledR}$ Andrew M. Allen ${ }^{1}$ \\ ${ }^{1}$ Department of Physiology, University of Melbourne, Victoria, 3010 Australia, ${ }^{2}$ Department of Anatomy and Neurosciences, University of Melbourne, \\ Victoria, 3010 Australia, ${ }^{3}$ Cardiovascular Medicine, School of Medicine, Flinders University, Bedford Park, South Australia, 5042 Australia, and ${ }^{4}$ Human \\ Physiology, School of Medicine, Flinders University, Bedford Park, South Australia, 5042 Australia
}

Brainstem catecholaminergic neurons play key roles in the autonomic, neuroendocrine, and behavioral responses to glucoprivation, yet the functions of the individual groups are not fully understood. Adrenergic C3 neurons project widely throughout the brain, including densely to sympathetic preganglionic neurons in the spinal cord, yet their function is completely unknown. Here we demonstrate in rats that optogenetic stimulation of C3 neurons induces sympathoexcitatory, cardiovasomotor functions. These neurons are activated by glucoprivation, but unlike the $\mathrm{C} 1$ cell group, not by hypotension. The cardiovascular activation induced by $\mathrm{C} 3$ neurons is less than that induced by optogenetic stimulation of $\mathrm{C} 1$ neurons; however, combined stimulation produces additive sympathoexcitatory and cardiovascular effects. The varicose axons of $\mathrm{C} 3$ neurons largely overlap with those of $\mathrm{C} 1$ neurons in the region of sympathetic preganglionic neurons in the spinal cord; however, regional differences point to effects on different sympathetic outflows. These studies definitively demonstrate the first known function of C3 neurons as unique cardiovasomotor stimulatory cells, embedded in the brainstem networks regulating cardiorespiratory activity and the response to glucoprivation.

Key words: channelrhodopsin; glucoprivation; rostral ventrolateral medulla; sympathetic nervous system

\section{Introduction}

Multiple regulatory systems enable tight control of glucose homeostasis to ensure adequate provision for essential physiological functions (Verberne et al., 2014). In response to reduced glucose, autonomic, neuroendocrine, and behavioral systems are activated to mobilize energy stores and increase energy intake. These include activation of adrenal catecholamine secretion, via increased adrenal sympathetic nerve activity, to mobilize energy stores. Although the central pathways involved in this response are being elucidated and our understanding remains incomplete, an important role for hindbrain catecholaminergic neurons is clear. Studies over many years by Ritter and colleagues demonstrate the importance of catecholaminergic cell groups in the medulla oblongata in many responses to glucoprivation (Ritter et al., 2001, 2011; Bugarith et al., 2005; Li et al., 2009, 2011). Lesions of rostrally projecting, catecholamine-synthesizing neurons decrease the food intake response to glucoprivation, whereas lesions

\footnotetext{
Received Aug. 1, 2014; revised Sept. 9, 2014; accepted Oct. 2, 2014.

Author contributions: C.M., C.P.S., D.A.W., C.R.A., I.J.L.-S., A.Y.F., and A.M.A. designed research; C.M., C.P.S., A.A.C., J.K.B., N.J., I.J.L.-S., and A.Y.F. performed research; C.M., C.P.S., D.A.W., C.R.A., I.J.L.-S., A.Y.F., and A.M.A. analyzed data; C.M., C.P.S., A.A.C., J.K.B., N.J., D.A.W., C.R.A., I.J.L.S., A.Y.F., and A.M.A. wrote the paper.

This work was supported by Australian National Health and Medical Research Council Project Grants 1029396 and 1025031 and Australian Research Council Discovery Project Grant DP1094301. C.M. is supported by a McKenzie Fellowship from the University of Melbourne. We thank Lee Travis for expert technical assistance.

The authors declare no competing financial interests.

Correspondence should be addressed to Dr. Andrew M. Allen, Department of Physiology, University of Melbourne, Victoria, 3010, Australia. E-mail: a.allen@unimelb.edu.au.

DOI:10.1523/JNEUROSCI.3179-14.2014

Copyright $\odot 2014$ the authors $\quad 0270-6474 / 14 / 3415110-13 \$ 15.00 / 0$
}

of the spinally projecting cells decrease adrenal medullary catecholamine secretion (Ritter et al., 2001; Bugarith et al., 2005; Li et al., 2011). Much of the focus resulting from these observations has centered on the role of adrenaline-synthesizing $\mathrm{C} 1$ neurons of the rostral ventrolateral medulla (RVLM), which are activated by glucoprivation (Ritter et al., 1998; Verberne and Sartor, 2010; Parker et al., 2013) and contribute to the excitation of adrenal sympathetic nerve activity.

Although the role of the $\mathrm{C} 1$ neurons is not disputed, the other medullary adrenaline-synthesizing cell groups, C2 and C3 neurons, are also activated by glucoprivation (Ritter et al., 1998). We recently mapped the distribution of projections from the dorsomedullary C3 cell group and showed that, like C1 neurons, C3 neurons project widely throughout the CNS, including to sympathetic preganglionic neurons (SPNs) of the spinal cord and hypothalamic and thalamic sites involved in homeostatic regulation of feeding (Sevigny et al., 2012). Similarly to C1 neurons, C3 neurons express the vesicular glutamate transporter 2 (VGluT2) (Stornetta et al., 2002), suggesting they are glutamatergic. VGlut2 and vesicular monoamine transporter 2 (VMAT2) immunoreactivity have been identified in C3 axon terminals in close apposition to SPNs within the thoracic intermediolateral cell column (IML), reinforcing their potential, yet undetermined, sympathoexcitatory function. Indeed, to date there is no described function for C3 neurons.

In this study, we characterize the projections of $\mathrm{C} 3$ subgroups and show that all groups are activated by glucoprivation, but not by hypotension. Using optogenetic stimulation, we demonstrate 
the first physiological function for C3 neurons as a sympathoexcitatory cell group. This function is compared with that of the more characterized $\mathrm{C} 1$ neuron group. Together, the data point to a role for $\mathrm{C} 3$ neurons as a new major component of the network responding to glucoprivation.

\section{Materials and Methods}

Animals. All experiments were conducted in accordance with the Australian National Health and Medical Research Council "Code of Practice for the Care and Use of Animals for Scientific Purposes" and were approved by the University of Melbourne Animal Experimentation Ethics and Biosafety Committee or by the Animal Welfare Committee of Flinders University. All experiments were performed on male Sprague Dawley (SD) rats ( $n=44,250-400 \mathrm{~g}$ for anatomy, $100-150 \mathrm{~g}$ for electrophysiology). Animals were housed with a $12 \mathrm{~h}$ light:dark cycle at a constant temperature $\left(22 \pm 1{ }^{\circ} \mathrm{C}\right)$ with ad libitum access to standard rat chow and water.

Induction of Fos immunoreactivity. 2-Deoxyglucose (2-DG) was used to induce neuroglucoprivation (Ritter et al., 1998). Pairs of rats were handled daily for 4-10 d before 2-DG or saline treatment. On the night before the experiment, the rats were deprived of food but had access to water ad libitum. The following morning, one rat received a subcutaneous injection of 2-DG ( $400 \mathrm{mg} / \mathrm{kg}$ in distilled water) and the other received distilled water. The rats were perfused with phosphate-buffered $4 \%$ formaldehyde $2 \mathrm{~h}$ after injection. 2-DG treatment does not affect blood pressure (Llewellyn-Smith et al., 2012).

Hydralazine (HDZ) treatment was used to lower blood pressure as described previously (Stornetta et al., 2001; Fenwick et al., 2006). Pairs of rats received either $\mathrm{HDZ}$ or saline. Baseline blood pressure was measured at $5 \mathrm{~min}$ intervals for $30 \mathrm{~min}$, and then $\mathrm{HDZ}(10 \mathrm{mg} / \mathrm{ml}$ diluted in 2 $\mathrm{mg} / \mathrm{ml}$ saline, $\mathrm{H}-1753$, Sigma Chemical) or saline was infused over a 1-2 min period. Arterial pressure and heart rate (HR) were continuously recorded for $5 \mathrm{~min}$ from the commencement of the infusion and then at 10 min intervals until $120 \mathrm{~min}$. Rats were deeply anesthetized and perfused immediately after the last blood pressure and HR measurements.

Surgical procedure for brainstem microinjections. Thirty to $60 \mathrm{~min}$ before all surgeries, rats were injected with a nonsteroidal, antiinflammatory agent (meloxicam, $1 \mathrm{mg} / \mathrm{kg}$, s.c., Metacam, Boehringer Ingelheim). For all surgical procedures, rats were lightly anesthetized by inhalation of isoflurane (Rhodia Australia) before intramuscular injection of a mixture of ketamine (60 mg/kg, i.m.; Lyppard, Dingley) and medetomidine $(250 \mu \mathrm{g} / \mathrm{kg}$, i.m.; Pfizer Animal Health). Once a deep surgical level of anesthesia was obtained, as evidenced by loss of the pedal withdrawal and corneal reflexes, the rats were placed in a stereotaxic frame with the skull either angled downward $\left(40^{\circ}\right.$, lentiviral injections) or horizontal between lambda and bregma (fluorescent microsphere injections).

Injections of fluorescent microspheres. Three animals received bilateral injections of fluorescent microspheres into both the pontine tegmental tract (green microspheres) and the IML of the third thoracic spinal segment (orange microspheres). Three animals received bilateral injections of green fluorescent microspheres into only the pontine tegmental tract, and three others received bilateral injections of orange microspheres into only the IML of T3. Three additional animals received unilateral injections into only the pontine tegmental tract (orange microspheres), and three others received unilateral injections into only the IML of T3.

For bilateral injections into the IML of T3, animals were placed in a stereotaxic frame as described above, and a midline incision was made along the upper thoracic spinal region. The brown adipose tissue was retracted, and the spinal process at T4 clamped and gently stretched to open the gap between vertebrae. Fluorescent orange-labeled microspheres $(540 \mathrm{~nm} / 560 \mathrm{~nm}$ excitation/emission wavelengths; Invitrogen; $10 \%$ in $0.9 \%$ sterile saline) were microinjected through a glass micropipette, which was placed $550 \mu \mathrm{m}$ lateral to midline. Successive injections ( $\sim 50-80 \mathrm{nl}$ each) were made from 0.3 to $1.2 \mathrm{~mm}$ below the surface of the cord at $0.3 \mathrm{~mm}$ intervals. Injections were also performed in the same pattern, $700 \mu \mathrm{m}$ lateral to midline to label axons of passage in the lateral white matter. These injections were repeated on the opposite side; all tissue layers were sutured and the animals allowed to recover.
Rats for dual retrograde-labeling experiments also received injections of fluorescent green-labeled microspheres $(505 \mathrm{~nm} / 515 \mathrm{~nm}$ excitation/ emission wavelengths; Invitrogen; $10 \%$ in $0.9 \%$ sterile saline) into the pontine tegmental tract at the same time as the spinal injections. A midline incision was made over the skull, and part of the skull was removed via trepination to allow access to the brain $2 \mathrm{~mm}$ anterior to the lambdoid suture and $\sim 3 \mathrm{~mm}$ on either side of the midline. After careful removal of the dura, microspheres were injected with a glass micropipette at coordinates encompassing the central, lateral, and ventral portions of the pontine tegmental tract, bilaterally. Injections of 50-80 nl were placed at $2 \mathrm{~mm}$ anterior to the lambdoid suture, and at the following coordinates bilaterally: $0.8 \mathrm{~mm}$ lateral ( $7 \mathrm{~mm}$ ventral to the cortical surface), $1.6 \mathrm{~mm}$ lateral (at $0.3 \mathrm{~mm}$ intervals between 7 and $5 \mathrm{~mm}$ ventral to the cortical surface), and $2.4 \mathrm{~mm}$ lateral (at $0.3 \mathrm{~mm}$ intervals between 6.5 and $5.5 \mathrm{~mm}$ ventral to the cortical surface). After all brain injections were completed, all wounds were closed with sterile sutures and rats revived via an intramuscular injection of atipamazole ( $1 \mathrm{mg} / \mathrm{kg}$; Pfizer Animal Health).

Unilateral injections of orange-fluorescent microspheres into T3 (three animals) or the pontine tegmental tract (three animals) were performed using the methods described above. After all injections, animals were allowed to recover in their home cages for $7-10 \mathrm{~d}$ and then perfused under deep anesthesia in preparation for histology.

Microinjection of lentiviruses. We used replication-deficient lentiviruses that are HIV-1-derived and pseudo-typed with the VSV-G envelope. A detailed description of the methods used to generate and characterize these viruses has been published previously (Chen et al., 2010). Transgene expression was under the control of a synthetic phox2selective promoter (PRSx8) (Card et al., 2006, 2011; Abbott et al., 2009b, 2012, 2013; Kanbar et al., 2010; Bruinstroop et al., 2012; Sevigny et al., 2012; Tang et al., 2014). Three different viruses were used: (1) Lv-PRSx8ChR2(E123T-H134R)-eYFP-WPRE to express mutant light-gated cation-selective channelrhodopsin-2 (ChR2) fused to the enhanced yellow fluorescent protein (YFP) in C3 and/or C1 neurons $\left(6.1 \times 10^{8}\right.$ infectious units/ml); (2) Lv-PRSx8-eGFP to express the enhanced GFP in C1 neurons $\left(8.3 \times 10^{8}\right.$ infectious units/ml); and (3) Lv-PRSx8-tdTomato to express the red fluorophore tdTomato in C3 neurons $\left(4.6 \times 10^{8}\right.$ infectious units/ml).

For all lentiviral injections, 21-d-old rats were anesthetized and placed in a stereotaxic frame as described above. A midline incision was made over the occipital bone, portions of the bone overlying the cerebellum were removed with a dental drill, and the atlanto-occipital membrane was opened to expose the calamus scriptorius, which was used as a reference point for stereotaxic coordinates. Glass micropipettes $(20-30 \mu \mathrm{m}$ tip diameter) enabled the recording of antidromic field potentials that were elicited by stimulating the mandibular branch of the facial nerve and were used to map the caudal and ventral edges of the facial nucleus, allowing precise targeting of C1 neurons (Abbott et al., 2009a, 2009b). These pipettes, connected to a picospritzer (World Precision Instruments), were used to microinject lentiviruses ( $80 \mathrm{nl}$ per injection site for ChR2 expression, $40 \mathrm{nl}$ per injection site for GFP/tdTomato expression, over $5 \mathrm{~min}$ ). Injections targeting $\mathrm{C} 1$ neurons were made unilaterally (right side), $1.5 \mathrm{~mm}$ lateral to the midline at the ventral edge of the facial field and $300 \mu \mathrm{m}$ dorsal to this. These injections were made at three rostrocaudal levels separated by $300 \mu \mathrm{m}$, the most rostral being just rostral to the caudal end of the facial field potential. Injections to target C3 neurons were made in the midline, at five rostrocaudal levels separated by $250 \mu \mathrm{m}$. The most caudal C3 injection was made $100 \mu \mathrm{m}$ rostral to the most rostral $\mathrm{C} 1$ injection. At each rostrocaudal site, three injections were made in the dorsoventral plane, each separated by $300 \mu \mathrm{m}$, and based upon the position of the facial field potential. The wound was closed with sterile sutures, and the animals revived via intramuscular injection of atipamazole ( $1 \mathrm{mg} / \mathrm{kg}$, Pfizer Animal Health). Animals used for optogenetic experiments were allowed to recover for $10 \mathrm{~d}$ before electrophysiological recordings, whereas animals used for neuronal tracing studies were killed 6 weeks after injection to optimize fluorophore labeling of axonal projections.

Working heart-brainstem preparation (WHBP). SD rats injected with Lv-PRSx8-ChR2-eYFP in C3 and C1 areas $(n=7)$, C3 only $(n=3)$, and $\mathrm{C} 1$ only $(n=3)$ were examined using the WHBP, which allows record- 
ings of cardiorespiratory activity (Paton, 1996; Paton et al., 2006; Simms et al., 2009; Marina et al., 2011; McBryde et al., 2013). Ten days after the injection of viral vectors, SD rats were anesthetized deeply with isoflurane until loss of paw withdrawal reflex. Animals were bisected below the diaphragm, exsanguinated, cooled in Ringer's solution on ice (composition in mM as follows: $125 \mathrm{NaCl}, 24 \mathrm{NaHCO}_{3}, 5 \mathrm{KCl}, 2.5 \mathrm{CaCl}_{2}, 1.25$ $\mathrm{MgSO}_{4}, 1.25 \mathrm{KH}_{2} \mathrm{PO}_{4}$, and 10 dextrose, $\mathrm{pH} 7.3$, after saturation with carbogen gas, $5 \% \mathrm{CO}_{2}, 95 \% \mathrm{O}_{2}$ ), and decerebrated precollicularly. All chemicals were purchased from Sigma-Aldrich. Lungs were removed, and the descending aorta was isolated and cleaned. Retrograde perfusion of the thorax and head was achieved via a double-lumen catheter $(\varnothing 1.25$ $\mathrm{mm}$, DLR-4, Braintree Scientific) inserted into the descending aorta. The perfusate was Ringer's solution containing Ficoll (1.25\%) warmed to $31^{\circ} \mathrm{C}$ and gassed with carbogen. The second lumen of the cannula was connected to a transducer to monitor perfusion pressure (PP) in the aorta. Neuromuscular blockade was established using vecuronium bromide added to the perfusate $(2-4 \mu \mathrm{g} / \mathrm{ml}$, Organon Teknika). Simultaneous recordings of phrenic nerve activity (PNA), thoracic sympathetic nerve activity (tSNA), between $\mathrm{T} 3$ and $\mathrm{T} 5$, and vagus nerve activity were obtained using glass suction electrodes, amplified ( $10 \mathrm{kHz}$, Neurolog), filtered (50-1500 kHz, Neurolog), digitized (CED), and recorded to hard disk using Spike2 (CED). HR was derived by using a window discriminator to trigger from the R-wave of the electrocardiogram recorded simultaneously through the phrenic nerve suction electrode.

Optogenetic stimulation. For the WHBP, ear and mouth bars were used to position the dorsal surface of the brainstem in a horizontal plane. Optical fibers (200 $\mu \mathrm{m}$ diameter; Doric Lenses) connected to a $473 \mathrm{~nm}$ DPSS Laser (Shanghai Laser \& Optics Century) were inserted vertically (dorsal approach) to photostimulate $\mathrm{C} 1$ neurons $(1.7 \mathrm{~mm}$ rostral, 1.6 $\mathrm{mm}$ lateral, $-2.0 \mathrm{~mm}$ ventral to calamus scriptorius), and on a $40^{\circ}$ angle to vertical (dorsal approach) to photostimulate C3 neurons $(2.0 \mathrm{~mm}$ rostral to calamus scriptorius, midline, tip touching the dorsal surface of the brainstem). A light meter (PM20A fiber power meter, Thorlabs) was used to measure light intensity, which was set at $10 \mathrm{~mW}$ as this was found to induce maximal effects in our experimental setup without any adverse effect on the tissue. Photostimulation trials consisted of the following: (1) frequency-response photostimulations to determine maximal effect ( 5 , 10, 20, and $50 \mathrm{~Hz}, 15 \mathrm{~ms}$ pulses, 600 pulses) (see Fig. 5); (2) maximal photostimulations ( $20 \mathrm{~Hz}, 15 \mathrm{~ms}$ pulses, 600 pulses); (3) low-frequency 1 $\mathrm{Hz}$ photostimulations ( $1 \mathrm{~Hz}, 15 \mathrm{~ms}$ pulses, 500 pulses); and (4) pairedpulse photostimulations $(0.2 \mathrm{~Hz}, 15 \mathrm{~ms}$ pulses, 100 paired pulses, $300 \mathrm{~ms}$ or $1000 \mathrm{~ms}$ interval between paired pulses).

Histology. Standard perfusion and postfixation protocols were performed as previously published (Llewellyn-Smith et al., 2012; Sevigny et al., 2012). Following cryoprotection (20\% sucrose in half-strength TBPS $+0.05 \%$ Thimerosal, $\mathrm{pH}$ 7.4), brains and spinal cord segments were cut coronally (30 $\mu \mathrm{m}$ sections for Fos studies, $40 \mu \mathrm{m}$ sections otherwise) or horizontally (spinal cord segments for the dual-viral tracing study, 40 $\mu \mathrm{m}$ sections) using a cryostat. Immunohistochemistry protocols were performed as previously published for fluorescence immunohistochemistry (Chen et al., 2010; Sevigny et al., 2012) and for peroxidase immunohistochemistry (Llewellyn-Smith et al., 2005, 2013). The only exception was for immunohistochemistry done on tissue from animals injected with fluorescent microspheres, where Triton exposure was reduced to avoid disruption of the latex microspheres. In this case, only the initial blocking steps included $0.1 \%$ Triton and Triton was omitted from the primary antibody incubation. The primary antibodies used here were as follows: rabbit anti-TH (1:5000, Millipore Bioscience Research Reagents, AB152), sheep anti-TH (1:1000, Millipore Bioscience Research Reagents, AB1542), mouse anti-D $\beta$ H (1:2500, Millipore Bioscience Research Reagents, MAB308), rabbit anti-VMAT2 (1:5000, Phoenix Laboratories, H-V004), sheep anti-neuropeptide Y (NPY) (1:2500, Millipore Bioscience Research Reagents, AB1583), chicken anti-GFP (1:5000, Abcam, AB13970), rabbit anti-DsRed (1:5000, Clontech Laboratories, catalog \#632496), goat anti-ChAT (1:1000 for fluorescent immunohistochemistry, 1:5000 for peroxidase immunohistochemistry, Millipore Bioscience Research Reagents, AB144P), rabbit anti-phenylethanolamine $N$-methyltransferase (PNMT) (1:30,000, kind gift of Dr Luc Denoroy), and rabbit anti-Fos (1:5000, Santa Cruz Biotechnology, SC-253, lot
F-131). The secondary antibodies for fluorescence immunohistochemistry, which were all obtained from Jackson ImmunoResearch Laboratories, except where noted, were Cy3-conjugated donkey anti-rabbit (1: 500), Cy3-conjugated donkey anti-mouse (1:500), AlexaFluor-488 goat anti-rabbit (1:500, Invitrogen), AlexaFluor-488 goat anti-mouse (1:500, Invitrogen), AlexaFluor-488 goat anti-chicken (1:500, Invitrogen), AlexaFluor-488 donkey anti-chicken (1:500), Cy5-conjugated donkey antigoat (1:500), and Cy5-conjugated donkey anti-rabbit (1:500). For immunohistochemical detection of TH fibers in the spinal cord, a rabbit anti-sheep biotinylated antibody was used (1:500, Vector Laboratories), followed by incubation with streptavidin-Cy5 antibody (1:1000). For peroxidase immunohistochemistry, biotinylated donkey anti-rabbit immunoglobulin or donkey anti-goat immunoglobulin (1:500) followed by ExtrAvidin-horseradish peroxidase conjugate (1:1500, Sigma) was used. For PNMT and ChAT double staining, a cobalt- and nickel-intensified DAB reaction stained PNMT-immunoreactive neurons black, and a Vector SG kit stained ChAT-immunoreactive neurons blue-gray. For Fos and PNMT double staining, a cobalt- and nickel-intensified DAB reaction stained Fos-immunoreactive neurons black, and an imidazoleintensified DAB reaction stained PNMT-immunoreactive neurons brown.

Bright-field, epifluorescence, and confocal microscopy. An Olympus BH-2 bright-field microscope connected to a Spot RT color camera (Diagnostic Instruments) was used to capture images of neurons labeled with peroxidase immunohistochemistry. Neurons for the Fos study were counted in 1:4 series of $30 \mu \mathrm{m}$ coronal sections. Neurons for anatomical characterization of C3 subgroups were counted in 1:6 series of $40 \mu \mathrm{m}$ coronal sections.

An Axio Imager D.1 microscope connected to an AxioCam MRc5 digital camera (Zeiss) was used to capture images of neurons labeled for ChR2-eYFP immunoreactivity and TH immunoreactivity. Neurons were counted on one in six series of $40 \mu \mathrm{m}$ coronal sections.

For the fluorescent microspheres study, sections containing TH immunoreactivity were initially viewed with a Zeiss LSM 510 META confocal microscope. Images were acquired with either a $40 \times$ IR-Achroplan (NA 0.80) water-immersion objective or a $100 \times$ IR-Achroplan (NA 1.25) oil-immersion objective. After confirmation with confocal microscopy that no TH-immunoreactive C3 neurons contained both fluorescent orange and fluorescent green microspheres, fluorescence microscopy was performed using an Axio Imager D.1 microscope connected to an AxioCam MRc5 digital camera (Zeiss) for observation of TH-immunoreactive C3 neurons containing either orange or greenfluorescent microspheres. For observation of orange fluorescent microspheres, a secondary antibody with green fluorophore (Alexa-488) was used to reveal TH immunoreactivity; and for observation of green fluorescent microspheres, a secondary antibody with red fluorophore (Cy3) was used to reveal TH immunoreactivity.

For comparison of axonal projections from $\mathrm{C} 3$ and $\mathrm{C} 1$ neurons to the IML, sections were viewed with a Zeiss LSM510 PASCAL confocal microscope. Sections labeled with AlexaFluor-488-, Cy3-, and Cy5conjugated probes were excited at $488 \mathrm{~nm}$ (argon laser), $543 \mathrm{~nm}$ and 633 $\mathrm{nm}$ (helium neon laser), respectively. Images of SPN clusters were acquired with a $63 \times$ IR-Achroplan (NA 1.0) oil-immersion objective, in a $Z$-stack array, acquiring up to 8 consecutive overlapping slices. All channels were acquired at a consistent pinhole setting of $1.0 \mu \mathrm{m}$. Each optical section was assessed for close apposition between axons labeled with $\mathrm{Cy} 3$ (C3) or AlexaFluor-488 (C1) and ChAT-immunoreactive SPNs. Maximum intensity projections of 4-6 image stacks were produced using the software Zeiss Zen Imager to better represent the distribution of C3 and C1 labeling in the IML.

Adobe Photoshop was used to optimize brightness and contrast of the digital images.

Data analysis and statistics. The physiological responses to stimulation of $\mathrm{C} 1$ and $\mathrm{C} 3$ neurons were obtained during maximal photostimulation, which was determined to be $20 \mathrm{~Hz}$. The data were measured during the entire photostimulation period and are presented as variations in $\delta$ values compared with the prestimulus control period (90 s). The signals were rectified and integrated with a $50 \mathrm{~ms}$ time constant. For lowfrequency photostimulation ( $1 \mathrm{~Hz}$ and paired-pulse protocols), the sig- 
A
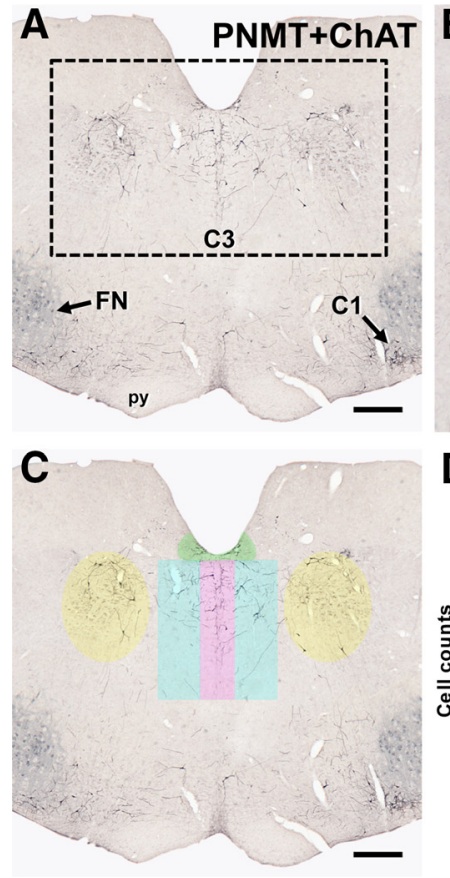

D

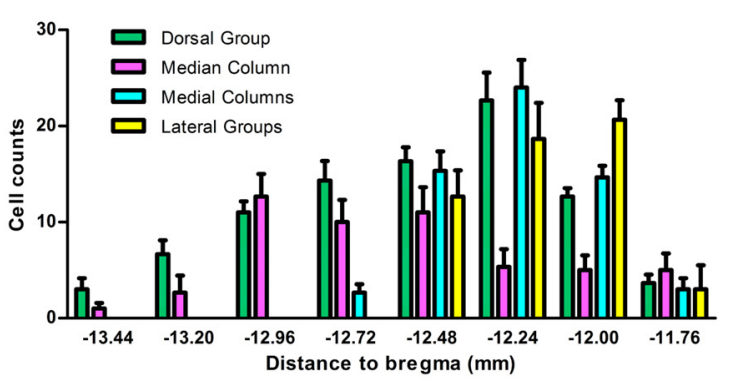

Figure 1. Organization of $C 3$ neurons in the dorsal medulla. $A$, Photomicrograph showing the distribution of neurons immunoreactive for PNMT (black) or ChAT (blue-gray) in a coronal section through the rostral medulla oblongata rostral to the caudal end of the facial motor nucleus (FN). PNMT-immunoreactive (3 neurons are diffusely distributed in the rostral dorsomedial medulla oblongata. At this level, the rostral end of the C1 cell group is visible ventromedial to FN. $\boldsymbol{B}$, Higher-magnification view of the dotted rectangle in $\boldsymbol{A}$, which contains the C 3 cell group. The lateral C 3 neurons lie medial to ChAT-immunoreactive neurons in the dorsal motor nucleus of vagus (arrows in the enlarged area). $\boldsymbol{C}$, The same section as in $\boldsymbol{A}$ with highlighting to delineate the different subgroups of $C 3$, which are differentiated on the basis of the spatial organization of their somata. The same color coding is used in the bar histogram $(\boldsymbol{D})$, which provides quantitative information about the rostrocaudal distribution of neurons that comprise the different $C 3$ subgroups. Rostrocaudal levels are relative to bregma. Data are mean $\pm \operatorname{SEM}(n=3)$. 4V, Fourth ventricle. Scale bars, $500 \mu \mathrm{m}$.

nals were rectified and integrated with a $5 \mathrm{~ms}$ time constant. Group data are presented as mean \pm SEM. Paired Student's $t$ tests were used to assess the specific effect of single cell group photostimulation; repeatedmeasures one-way ANOVA, followed by the Holm-Sidak post hoc multiple-comparison test, was used to compare the effects of photostimulation of the different cell groups (SigmaPlot 12). $p<0.05$ represents statistically significant differences.

\section{Results}

\section{Anatomical characterization of $\mathrm{C} 3$ neurons}

Immunoreactivity for PNMT characterizes the adrenergic cell groups and reveals that $\mathrm{C} 3$ neurons are located in the dorsomedial medulla oblongata (Fig. $1 A, B$ ), extending rostrocaudally in adult $\mathrm{SD}$ rats $(n=3)$ for $\sim 1.7 \mathrm{~mm}$. Counts taken from every sixth $40 \mu \mathrm{m}$ section throughout the C3 nucleus reveal $257 \pm 7(n=3)$ PNMTimmunoreactive neurons in the $\mathrm{C} 3$ nucleus. $\mathrm{C} 3$ neurons stretch from the caudal end of the fourth ventricle (bregma $-13.44 \mathrm{~mm}$ ) to the caudal-most portion of the dorsal cochlear nucleus and the rostral tip of raphe obscurus (bregma $-11.76 \mathrm{~mm}$ ).

Within this medullary region, C3 neurons can be grouped into four distinct subregions: the dorsal group $(35.6 \pm 1.2 \%$ of all C3 neurons), the median column (19.7 $\pm 1.2 \%)$, the medial columns ( $24.9 \pm 0.9 \%$, counted bilaterally), and the lateral groups $(19.8 \pm 1.3 \%$, counted bilaterally) (Fig. 1C,D). The dorsal group consists of neurons located along the ventral surface of the fourth ventricle and extends throughout the entire rostrocaudal limits of the $\mathrm{C} 3$ nucleus, with the highest number of cells found at bregma $-12.24 \mathrm{~mm}$ (Fig. 1C,D). The median column extends down the midline for $\sim 1.0-1.2 \mathrm{~mm}$, with the ventral portions overlapping with raphe obscurus. This column also spans the full rostrocaudal extent of the C3 nucleus, with the highest number of neurons occurring at bregma -12.96 $\mathrm{mm}, \sim 0.7 \mathrm{~mm}$ caudal to the highest concentration of the dorsal group neurons. The medial columns directly flank the median column. Although these two subgroups could potentially be combined into one "midline cluster," the medial columns only occur in the most rostral portion of the C3 nucleus (bregma -12.72 to bregma $-11.76 \mathrm{~mm}$ ), with the caudal extent appearing just rostral to the peak of the median column neurons. The highest number of neurons appears at bregma $-12.24 \mathrm{~mm}$, coinciding with the highest concentration of dorsal group neurons. The final subgroup of $\mathrm{C} 3$ neurons, the lateral group, is anatomically isolated from the other $\mathrm{C} 3$ neurons, lying $\sim 1.5 \mathrm{~mm}$ lateral to the midline, just ventral to the nucleus of the solitary tract (Fig. $1 B-D$ ). Although these neurons are located closer to the $\mathrm{C} 2$ nucleus than the central portions of C3, their existence outside of the boundaries of the nucleus of the solitary tract, defined as being dorsal and lateral to the rostral-most dorsal vagal motor nucleus (Fig. $1 B$, inset), groups them into the C3 population. The lateral group is only apparent from bregma -12.48 to bregma $-12.00 \mathrm{~mm}$, with the peak density occurring rostrally (bregma $-12.00 \mathrm{~mm}$; Fig. $1 D)$.

While defined by the expression of PNMT, C3 neurons are also dopamine $\beta$-hydroxylase $(\mathrm{D} \beta \mathrm{H})$ - and tyrosine hydroxylase (TH)-immunoreactive. A majority (89.4 $\pm 7.3 \%)$ of all $\mathrm{D} \beta \mathrm{H}$ immunoreactive $\mathrm{C} 3$ cell bodies were also VMAT2-immunoreactive (data not shown). There was no significant difference in the proportion of neurons immunoreactive for VMAT2 between individual C3 subgroups. We also tested immunoreactivity for NPY, a marker of catecholaminergic neurons involved in the glucoregulatory response (Bugarith et al., 2005; Li et al., 2009). Most C3 neurons were immunoreactive for NPY $(92.6 \pm 2.3 \%)$, with no significant variation between subgroups (data not shown).

\section{Selective projection pattern of $\mathrm{C} 3$ subgroups}

To characterize the projection patterns of the four subgroups of C3 neurons, injections of microspheres labeled with two different fluorophores were made either bilaterally $(n=3)$ or unilaterally $(n=3)$ into the pontine tegmental tract, or the IML at the third thoracic spinal segment. Injections into the pontine tegmental tract, designed to retrogradely label rostrally projecting C 3 neurons, encompassed the lateral, central, and ventral portions of the tract $2 \mathrm{~mm}$ rostral to the lambdoid suture. Injections into the thoracic spinal cord encompassed the IML, as well as the dorsolateral portions of the white matter, to retrogradely label bulbospinal C3 neurons. Injection sites were confirmed via fluorescent microscopy (data not shown) and showed little variation between animals. No TH-immunoreactive neurons were observed to contain both retrograde tracers (Fig. $2 A-D$ ), suggesting that individ- 

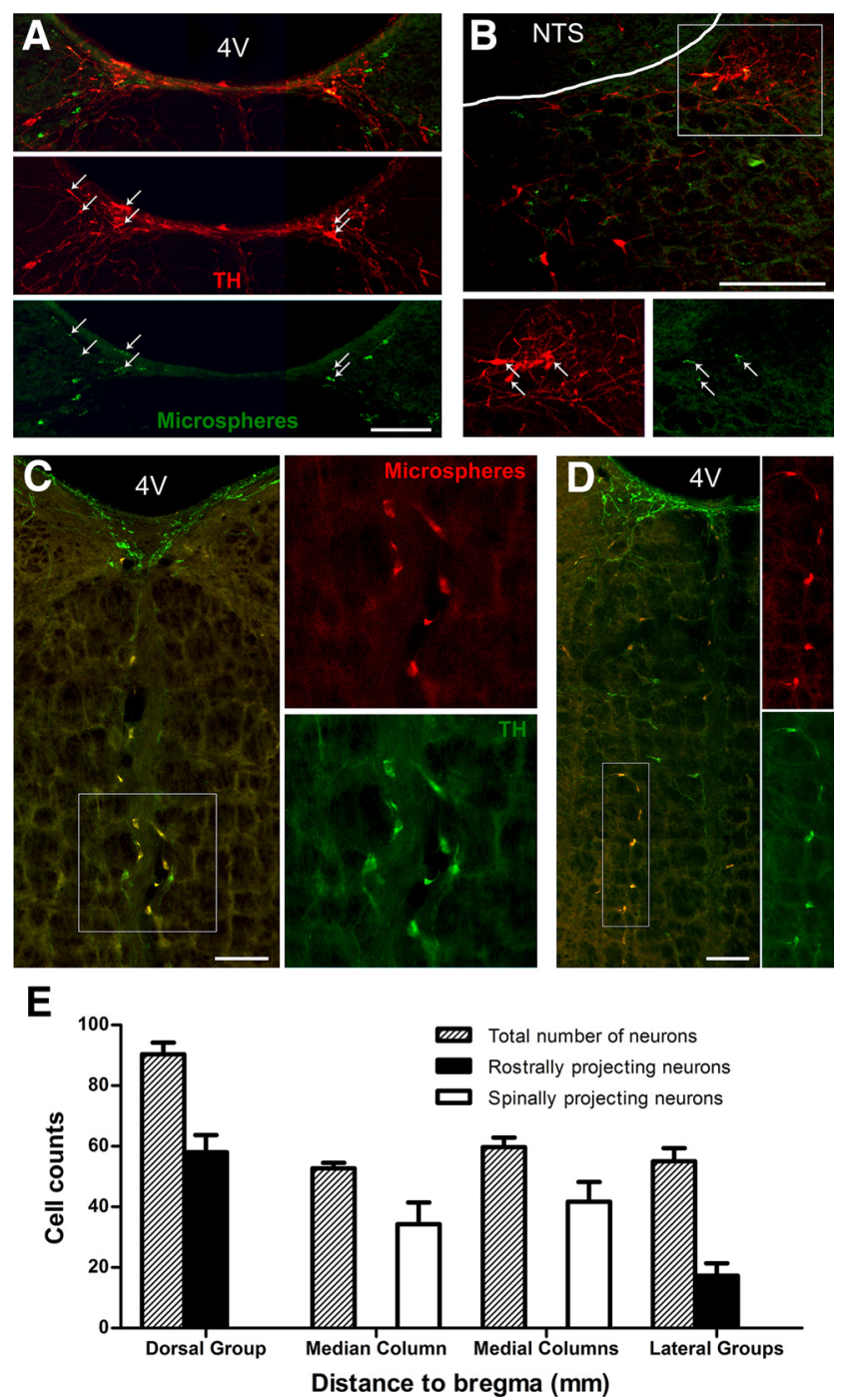

Figure 2. The dorsal and lateral C3 subgroups project rostrally; the median and medial C3 subgroups project caudally. Retrograde transport of green fluorescent microspheres injected into the pontine tegmental tract labels red $\mathrm{TH}$-immunoreactive 3 neurons in the dorsal $(\boldsymbol{A})$ and lateral (B) subgroups only. Merged images (top) and arrows indicate neurons containing both fluorescent microspheres and TH immunoreactivity. $\boldsymbol{B}$, Bottom panels, Enlargement of the boxed area in the top panel. Orange fluorescent microspheres (red) injected into the IML at the third thoracic spinal segment label green TH-immunoreactive $(3$ neurons in the median $(\boldsymbol{C})$ and medial $(\boldsymbol{D})$ subgroups only. In the merged images (left panels), doublelabeled neurons appear yellow. $\boldsymbol{C}, \boldsymbol{D}$, Right panels, Enlargement of the boxed area in the left panel. $\boldsymbol{D}$, In this example, the TH-immunoreactive C3 neurons in the left medial column were retrogradely labeled from unilateral injections of orange fluorescent microspheres (red) in the right IML. E, Bar histogram showing average raw cell counts of total C3 neurons (dashed bars), rostrally projecting (3 neurons (black bars), and spinally projecting $(3$ neurons (white bars) in each of the four subgroups. Each bar represents mean cell counts throughout each subgroup \pm SEM $(n=3)$. $4 \mathrm{~V}$, Fourth ventricle; NTS, nucleus of the tractus solitarius. Scale bars, $200 \mu \mathrm{m}$.

ual C3 neurons are unlikely to project to both rostral and spinal regions.

Rostrally projecting C3 neurons were located in the dorsal and lateral cell groups $(64.4 \pm 3.8 \%$ and $36.5 \pm 7.6 \%$ of all dorsal and lateral group C3 neurons, respectively; Fig. 2A,B,E). There were no rostrally projecting $\mathrm{TH}$-immunoreactive neurons within the median or medial columns. Conversely, all bulbospinal C3 neurons occurred in the median and medial columns. Of all TH-immunoreactive neurons in the median column and medial columns, $73.2 \pm 6.2 \%$ and $69.7 \pm 5.2 \%$, respectively, were bulbospinal (Fig. 2C-E). Many neurons not immunoreactive for $\mathrm{TH}$ within the boundaries of all four $\mathrm{C} 3$ subregions were also observed to have spinally or rostrally projecting axons and did not obey the same exclusive projection patterns.

Unilateral injections of retrograde tracers were performed to determine the extent of lateralization for spinally or rostrally projecting $\mathrm{C} 3$ neurons in the medial columns and lateral groups. In the lateral groups, $54.3 \pm 6.2 \%$ of rostrally projecting neurons projected contralaterally. In addition, $81.2 \pm 5.4 \%$ of bulbospinal $\mathrm{C} 3$ neurons in the medial columns projected contralaterally (Fig. $2 D$ ). Because injections were unilateral, retrogradely labeled neurons located contralateral to the injection sites in either group could potentially project bilaterally.

\section{Glucoprivation, but not hypotension, strongly activates C3 neurons}

To determine whether $\mathrm{C} 3$ neurons are activated by sympathoexcitatory challenges, we treated rats with either the antimetabolic glucose analog 2-DG $(400 \mathrm{mg} / \mathrm{kg})$ to induce glucoprivation or the vasodilator HDZ (10 mg/kg) to induce hypotension, and counted Fos-immunoreactive nuclei in PNMT-immunoreactive C3 neurons.

Treatment with 2-DG induced Fos expression in $\sim 60 \%$ of C3 neurons $(76.0 \pm 6.1$ PNMT + Fos vs $127.5 \pm 4.5$ PNMT-only immunoreactive neurons, $n=4$ ), and these were located in all subgroups (Fig. $3 A-D$ ). Fos immunoreactivity was not observed in 2-DG-sham animals $(0.8 \pm 0.8$ PNMT + Fos vs $219.5 \pm 15.5$ PNMT-only immunoreactive neurons, $n=4$ ). Treatment with HDZ induced very little Fos expression in C3 neurons (Fig. $3 G$ ), with an average of $7 \%$ of $\mathrm{C} 3$ neurons showing Fos immunoreactivity $(17.5 \pm 3.3$ PNMT + Fos vs $230.3 \pm 12.3$ PNMT-only immunoreactive neurons, $n=4)$. No Fos-immunoreactive neurons were observed in the HDZ-sham animals $(1.5 \pm 1.3$ PNMT + Fos vs $208.3 \pm 34.3$ PNMT-only immunoreactive neurons, $n=4)$. By contrast, RVLM C1 neurons, present in the same brainstem sections as $\mathrm{C} 3$ neurons (Fig. $3 E$ ), showed strong Fos immunoreactivity in response to $\mathrm{HDZ}$ treatment (Fig. $3 F, H$ ).

\section{Optogenetic stimulation of $\mathrm{C} 3$ neurons reveals their sympathoexcitatory function}

Because C3 neurons from the median and medial subgroups project to the IML and are activated by glucoprivation, we used optogenetic stimulation of C3 neurons to determine whether they modulate sympathetic activity. Twenty-one-day-old SD rats received microinjections of a lentiviral vector $(\mathrm{Lv})$ expressing a point mutated (E123T-H134R) form of ChR2 fused to enhanced YFP, abbreviated to Lv-PRSx8-ChR2-YFP, into either the C3 region $(n=3)$, the $\mathrm{C} 1$ region (unilaterally, $n=3$ ), or both the C3 and $\mathrm{C} 1$ regions $(n=7)$. After microinjection in the $\mathrm{C} 3$ region, expression was limited to the dorsal, median, and medial subgroups of $\mathrm{C} 3$ (Fig. $4 \mathrm{~A}$ ) and occurred in $\sim 50 \%$ of $\mathrm{C} 3$ neurons. A few non- $\mathrm{TH}$-immunoreactive $\mathrm{ChR} 2$-positive neurons were also observed in some sections, in the midline ventral to the $\mathrm{C} 3$ subgroups, $>1.5 \mathrm{~mm}$ ventral to the floor of the fourth ventricle at the level of the raphe obscurus.

Ten days after lentivirus injections, we used the WHBP to investigate C3 function. Maximal $(20 \mathrm{~Hz}, 15 \mathrm{~ms}$ pulses, 600 pulses, $10 \mathrm{~mW}$ light intensity; Fig. $5 \mathrm{~K}, L)$ photostimulation of C3 neurons significantly increased tSNA $(+0.29 \pm 0.07 \mu \mathrm{V}, p=$ 0.010 ; Fig. $5 A, B)$, PP $(+1.6 \pm 0.3 \mathrm{mmHg}, p=0.002$; Fig. $5 A, C)$, HR $(+4.7 \pm 1.9 \mathrm{bpm}, p=0.048$; Fig. $5 A, D)$, and inspiratory phrenic nerve bursting frequency (PNA, $+1.3 \pm 0.2$ bursts $/ \mathrm{min}$, $p=0.002$; Fig. $5 A, E$ ). Photostimulation of $\mathrm{C} 3$ neurons produced 


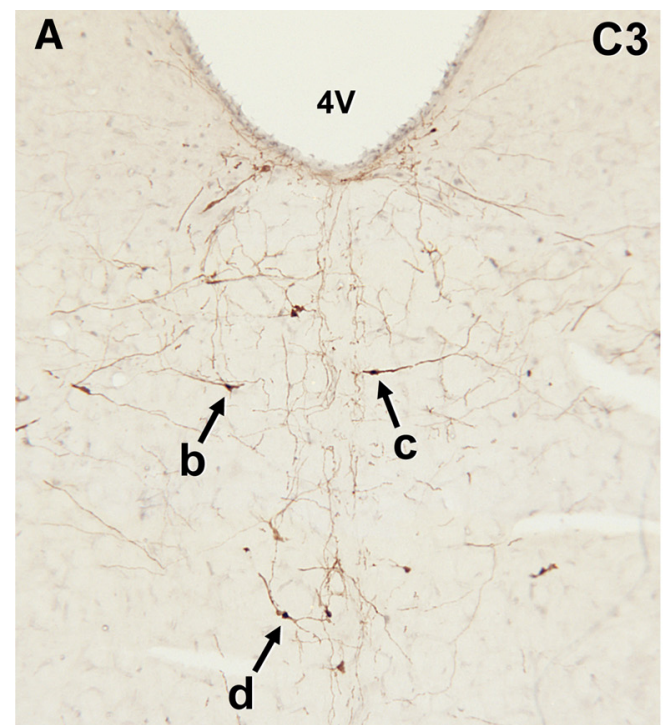

\section{Fos-2DG+PNMT}
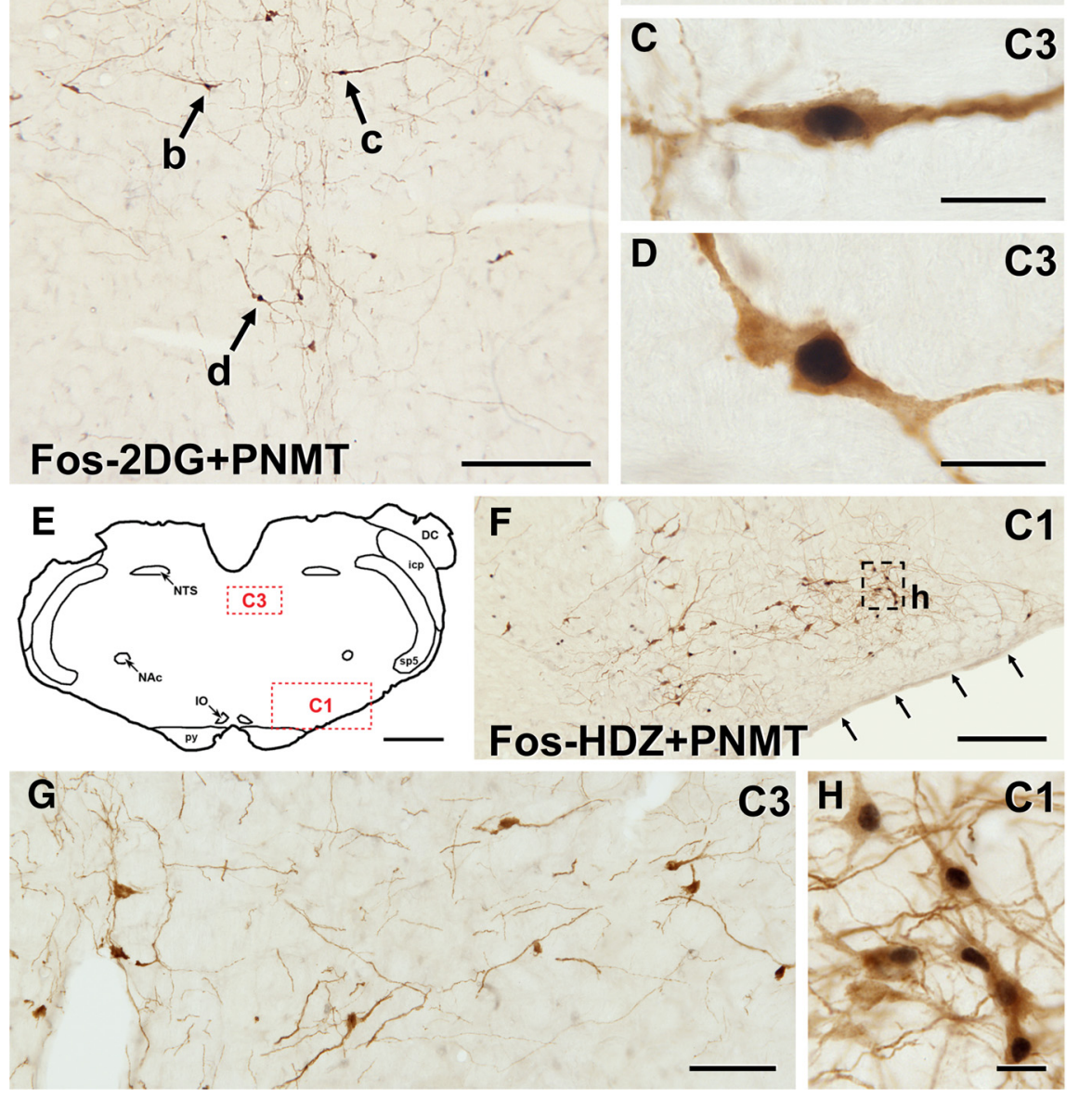

Figure 3. Many C 3 neurons express Fos after 2-DG, but not after HDZ. Photomicrographs of coronal sections double-stained for PNMT (brown) and Fos (black). A, After 2-DG treatment, which induces glucoprivation, many $(3$ neurons in all subgroups show immunoreactivity for Fos. $\boldsymbol{B}-\boldsymbol{D}$, Higher-magnification images of the neurons indicated by arrows $b-d$ in $\boldsymbol{A}$. $\boldsymbol{E}$, Diagram of the medulla oblongata with doted rectangles (red) showing the position of the enlargements in $\boldsymbol{F}(\mathrm{C} 1)$ and in $\boldsymbol{G}(\mathrm{C} 3)$. $\boldsymbol{F}$, After HDZ treatment, which induces hypotension, many brown $\mathrm{C} 1$ neurons show black Fos immunoreactivity in their nuclei. Arrows indicate the ventral surface of the medulla oblongata. $\mathbf{G}$, In contrast, in the same section, very few C3 neurons contain black, Fosimmunoreactive nuclei. $\boldsymbol{H}$, Higher-magnification view of the dotted square in $\boldsymbol{F}$, showing Fos-immunoreactive nuclei in PNMTimmunoreactive $\mathrm{C} 1$ neurons. $4 \mathrm{~V}$, Fourth ventricle; $D C$, dorsal cochlear nucleus; icp, inferior cerebellar peduncle; 10 , inferior olive; $\mathrm{NAc}$, compact formation of the nucleus ambiguous; py, pyramidal tract; $\mathrm{Sp} 5$, spinal trigeminal tract. Scale bars: $\boldsymbol{A}, \boldsymbol{F}, 250 \mu \mathrm{m} ; \boldsymbol{B}-\boldsymbol{D}$, $\boldsymbol{H}, 20 \mu \mathrm{m} ; \boldsymbol{E}, 1 \mathrm{~mm} ; \mathbf{G}, 100 \mu \mathrm{m}$.

the same effects in animals injected with Lv-PRSx8-ChR2-YFP only in the $\mathrm{C} 3$ region compared with animals injected in both the $\mathrm{C} 3$ and $\mathrm{C} 1$ regions. Photostimulation of the $\mathrm{C} 3$ region in animals injected only in the $\mathrm{C} 1$ region did not alter any measured parameters.

\section{Comparison of the response to maximal photostimulation of $\mathrm{C} 3$ and $\mathrm{C} 1$ neurons}

To determine the importance of $\mathrm{C} 3$ sympathoexcitatory function, we compared it with the effects produced by optogenetic stimulation of the $\mathrm{C} 1$ neurons. To transfect $\mathrm{C} 1$ neurons, we targeted the rostral part of the RVLM, caudal to the facial nucleus (Fig. $4 C, D$ ), which contains the bulk of spinally projecting $\mathrm{C} 1$ neurons (Jeske and McKenna, 1992). Expression of ChR2 in the
1

C1 region extended from $0.5 \mathrm{~mm}$ rostral to $1 \mathrm{~mm}$ caudal to the caudal pole of the facial nucleus. Over this rostrocaudal region, $\sim 40 \%$ of $\mathrm{C} 1$ neurons expressed ChR2 (Fig. 4D). Similarly to C3, a proportion of non-TH-immunoreactive ChR2positive neurons was also counted in the RVLM, mostly at the caudal and ventral edges of the facial nucleus, corresponding to retrotrapezoid nucleus Phox2b-positive cells (Abbott et al., 2012).

We compared the effects of maximal photostimulation of $\mathrm{C} 1$ neurons alone, $\mathrm{C} 3$ neurons alone, or $\mathrm{C} 1$ and $\mathrm{C} 3$ neurons together $(\mathrm{C} 1+\mathrm{C} 3)($ Fig. $5 F-L)$. The effect of different frequencies $(5-50 \mathrm{~Hz})$ of $\mathrm{C} 1$ and $\mathrm{C} 3$ photostimulation on $\mathrm{SNA}$ and $\mathrm{PP}$ was compared, and maximal activation occurred at $20 \mathrm{~Hz}$ stimulation (Fig. $5 K, L)$. Similarly to $\mathrm{C} 3$ photostimulation, $\mathrm{C} 1$ and $\mathrm{C} 1+\mathrm{C} 3$ photostimulation significantly increased tSNA $(+0.47 \pm 0.10$ and $+0.66 \pm 0.16 \mu \mathrm{V}, p=0.009$ and $p=$ 0.008 , respectively; Fig. $5 G)$, $\mathrm{PP}(+2.0 \pm$ 0.4 and $+2.3 \pm 0.5 \mathrm{mmHg}, p=0.003$ and $p=0.010$, respectively; Fig. $5 H)$, and PNA frequency $(+2.2 \pm 0.3$ and $+1.8 \pm$ 0.7 bursts $/ \mathrm{min}, p<0.001$ and $p=0.023$, respectively; Fig. 5I). Contrary to C3 photostimulation, $\mathrm{C} 1$ and $\mathrm{C} 1+\mathrm{C} 3$ photostimulation only caused a tendency to increase HR that did not reach significance $(+4.2 \pm 1.6$ and $+5.5 \pm 3.5 \mathrm{bpm}$, $p=0.122$ and $p=0.201$, respectively; Fig. $5 J)$. There was no significant difference between the effects produced by $\mathrm{C} 1$ and $\mathrm{C} 3$ photostimulation, although $\mathrm{C} 1$ tended to induce greater increases in tSNA, PP, and PNA frequency $(p=0.074, p=$ 0.081 , and $p=0.304$, respectively; Fig. $5 G, H, J) . C 1+\mathrm{C} 3$ photostimulation induced greater increases in tSNA and PP compared with $\mathrm{C} 3$ photostimulation alone ( $p=0.006$ and $p=0.030$, respectively; Fig. 5G,H), demonstrating a combinatorial sympathoexcitatory effect between $\mathrm{C} 1$ and $\mathrm{C} 3$ neurons. Vagus nerve activity was also recorded as a parasympathetic output, but neither $\mathrm{C} 1$, nor $\mathrm{C} 3$, nor $\mathrm{C} 1+\mathrm{C} 3$ photostimulation had any effect on its discharge amplitude during either respiratory phase, whereas respiratory-related (inspiratory and postinspiratory) activities increased in frequency in pace with PNA (data not shown).

\section{Different patterns of SNA activation by $\mathrm{C} 3$ and $\mathrm{C} 1$ neurons}

To determine whether $\mathrm{C} 3$ neurons shared the same sympathoexcitatory properties as $\mathrm{C} 1$ neurons, $1 \mathrm{~Hz}$ photostimulation $(15 \mathrm{~ms}$ pulses, 500 pulses, $10 \mathrm{~mW}$ light intensity) of C3 and C1 was performed. Pulse-triggered averages of tSNA revealed differences in the pattern of tSNA activation by $\mathrm{C} 3$ and $\mathrm{C} 1$ neurons (Fig. $6 A-C)$. The latency to peak tSNA activation induced by $\mathrm{C} 3$ photostimulation was almost double that of $\mathrm{C} 1$ photostimulation 

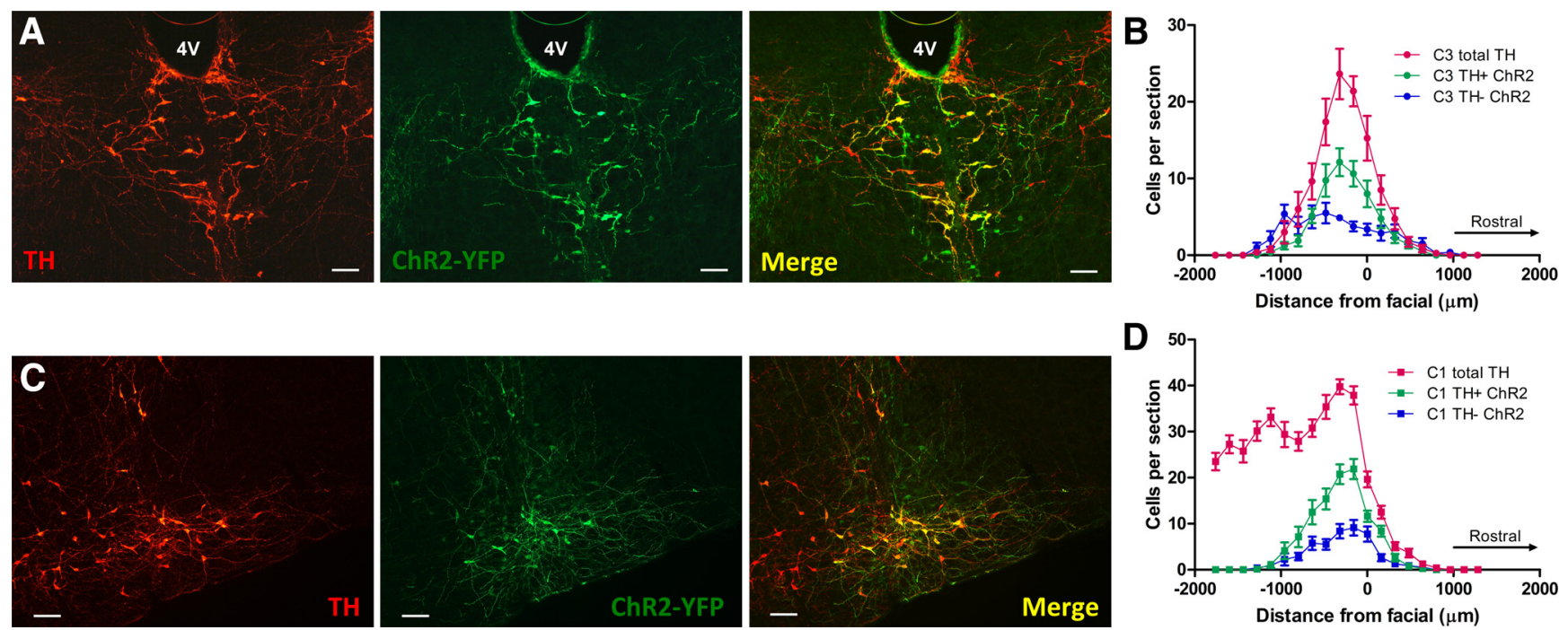

Figure 4. ChR2 expression in $\mathrm{C} 3$ and $\mathrm{C} 1$ neurons. Epifluorescence images of $40 \mu \mathrm{m}$ coronal sections showing ChR2-YFP immunoreactivity (green) in TH-immunoreactive (red) neurons in $C 3(\boldsymbol{A})$ and $C 1$ ( $C$, unilateral injection) cell groups, $10 \mathrm{~d}$ after Lv-PRSx8-ChR2-YFP injections. Note the high, but not absolute, specificity of the PRSx8 promoter in the merged images. $\boldsymbol{B}, \boldsymbol{D}$, Cell counts of total TH-immunoreactive cells (red), TH-immunoreactive and ChR2-YFP-immunoreactive cells (TH ${ }^{+}$ChR2, green), and non-TH-immunoreactive ChR2-YFPimmunoreactive cells (TH ${ }^{-}$ChR2, blue) in both C 3 and $(1$ areas of lentivirus injections. " 0 " in the $x$-axis indicates the caudal end of the facial nucleus. Data are mean \pm SEM $(n=7)$. $4 \mathrm{~V}$, Fourth ventricle. Scale bars, $100 \mu \mathrm{m}$.

$(115 \pm 4$ vs $68 \pm 4 \mathrm{~ms}$, respectively, $p<0.001$; Fig. $6 A, B)$. These differences in latencies were not altered by dual C1 + C3 photostimulation, and the burst timing and shape differences enabled the segregation of burst peaks caused by photostimulation of either cell group (for examples of $\mathrm{C} 1+\mathrm{C} 3$ low-frequency photostimulation traces, see Fig. $6 D, F)$. C1 photostimulation produced larger bursts of tSNA compared with $\mathrm{C} 3$ photostimulation $(6.73 \pm 1.74$ vs $4.48 \pm 0.79 \mu \mathrm{V}$, respectively, $p=0.031$; Fig. $6 A, C)$, a difference also present in the respective tSNA peaks during $\mathrm{C} 1+\mathrm{C} 3$ photostimulation $(7.97 \pm 2.73$ vs $4.88 \pm 1.23$ $\mu \mathrm{V}$, respectively; $\mathrm{C} 1$ and $\mathrm{C} 3$ peaks of $\mathrm{tSNA}$ activation, $p=0.043$; Fig. $6 A, C)$. Both $\mathrm{C} 1$ and $\mathrm{C} 3$ photostimulation-induced tSNA peaks were followed by long-lasting reductions in tSNA, with significantly greater reduction after $\mathrm{C} 1$ and $\mathrm{C} 1+\mathrm{C} 3$ photostimulation compared with $\mathrm{C} 3$ photostimulation alone $(15.4 \pm 3.1 \%, 16.5 \pm 3.2 \%$, and $9.5 \pm 1.5 \%$ compared with baseline, respectively; $\mathrm{C} 1$ vs $\mathrm{C} 3, p=0.020 ; \mathrm{C} 1+\mathrm{C} 3$ vs $\mathrm{C} 3, p=$ 0.010; $\mathrm{C} 1$ vs $\mathrm{C} 1+\mathrm{C} 3, p=0.572)$. The reduction in tSNA following C3 photostimulation was maximal $266 \pm 4 \mathrm{~ms}$ after light onset, which was delayed compared with that following $\mathrm{C} 1$ photostimulation $(240 \pm 4 \mathrm{~ms}, p=0.002)$ or $\mathrm{C} 1+\mathrm{C} 3$ photostimulation $(251 \pm 6 \mathrm{~ms}, p=0.049)$. Times to return to prestimulus SNA levels after C3, C1, or C1 + C3 photostimulation were not significantly different $(448 \pm 6,440 \pm 17$, and $474 \pm 19 \mathrm{~ms}$, respectively).

This period of poststimulus SNA depression has been shown with $\mathrm{C} 1$ optogenetic stimulation to decrease the amplitude of a second evoked SNA activation (Abbott et al., 2009b). We used a paired-pulse protocol to determine whether this was also the case with C3 neurons. Interestingly, paired-pulse photostimulation $(0.2 \mathrm{~Hz}, 15 \mathrm{~ms}$ pulses, 100 paired-pulse stimulations, $10 \mathrm{~mW}$ light intensity) with a $300 \mathrm{~ms}$ interval caused a tendency for an increase in the amplitude of the C3 photostimulation-induced second peak compared with the first peak (104\% for C3 photostimulation, $108 \%$ for the $\mathrm{C} 3 \mathrm{tSNA}$ peak of $\mathrm{C} 1+\mathrm{C} 3$ photostimulation, not significant; Fig. $6 D, E$ ). As described previously, there was a significant decrease in the amplitude of the $\mathrm{C} 1$ photostimulationinduced second peak compared with the first peak ( $91 \%$ for $\mathrm{C} 1$ photostimulation, $92 \%$ for the $\mathrm{C} 1 \mathrm{tSNA}$ peak of $\mathrm{C} 1+\mathrm{C} 3$ photostimulation, $p=0.013$ and 0.047 , respectively). Paired-pulse photostimulation with a $1000 \mathrm{~ms}$ interval had no effect on peak tSNA activation amplitudes, although there was a tendency for larger second peaks for both C1 and C3 photostimulationinduced tSNA peaks during the $\mathrm{C} 1+\mathrm{C} 3$ photostimulation protocol (Fig. $6 F, G$ ). Latencies between onset of stimulation and peak of tSNA activation were unaltered in the paired-pulse protocols.

\section{Comparison of the distribution of varicose axons in the IML} derived from $\mathrm{C} 3$ and $\mathrm{C} 1$ neurons

We sought to determine whether the different sympathoexcitatory characteristics of $\mathrm{C} 3$ and $\mathrm{C} 1$ neurons might be explained by a different projection pattern of these cells toward SPNs in the IML. In 21-d-old SD rats $(n=3)$, the lentiviral vector $\mathrm{Lv}$-PRSx8-tdTomato was injected in the $\mathrm{C} 3$ region, and the lentiviral vector Lv-PRSx8-GFP was injected unilaterally in the $\mathrm{C} 1$ region. Six weeks after injections, tdTomato and GFP soma expression profiles were similar to that of ChR2 for the respective nuclei, with $60 \pm 8 \%$ of $\mathrm{C} 3$ neurons expressing tdTomato, $53 \pm 10 \%$ of $\mathrm{C} 1$ neurons expressing GFP, and a small proportion of non-TH-immunoreactive neurons expressing fluorophores in both nuclei. Overall, an equal number of $\mathrm{C} 3$ and $\mathrm{C} 1$ neurons were labeled with fluorophores (61 \pm 5 vs $65 \pm 2$ neurons, for C3 and C1, respectively, counted at $240 \mu \mathrm{m}$ coronal intervals).

Horizontal and coronal sections of the T1-T5 spinal segments were used to compare the distribution of varicose axons within the IML derived from C3 and C1 neurons. Sections colabeled for $\mathrm{TH}$, tdTomato, and GFP immunoreactivity showed that all C3 axons to the spinal cord were $\mathrm{TH}$-immunoreactive, and the majority $(>80 \%)$ of $\mathrm{Cl}$ axons were $\mathrm{TH}$-immunoreactive (data not shown). This latter variation in $\mathrm{TH}$ immunoreactivity in $\mathrm{C} 1$ terminals correlates with the proportion of $\mathrm{C} 1$ somata in the RVLM that are immunoreactive for TH. Another set of sections was colabeled for tdTomato, GFP, and ChAT immunoreactivity, to colabel $\mathrm{C} 3$ and $\mathrm{C} 1$ projections with the SPNs of 
A ${ }_{\text {Laser }}^{\left.\text {ARm }{ }_{315}^{335}\right]}$ $\left.\mathrm{s}_{(\mu \mathrm{V})}^{3.5}{ }_{1.5}^{3}\right]$ dwy

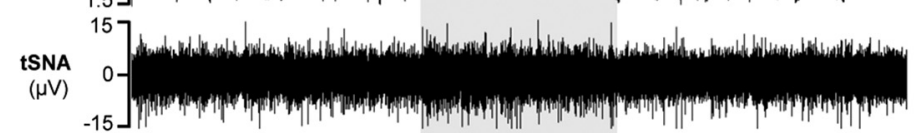

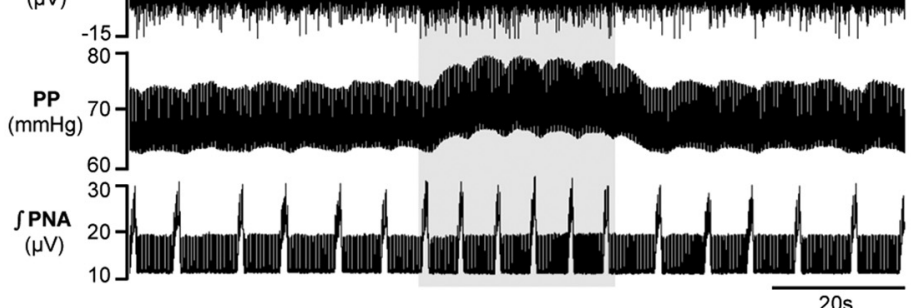

B

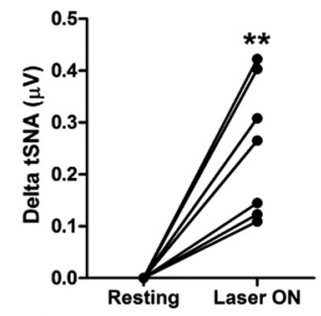

D

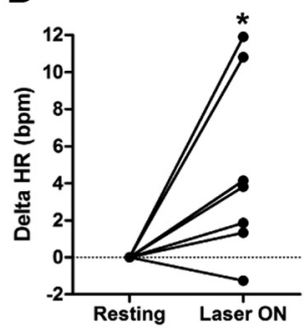

C

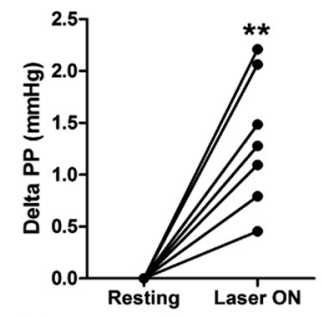

E

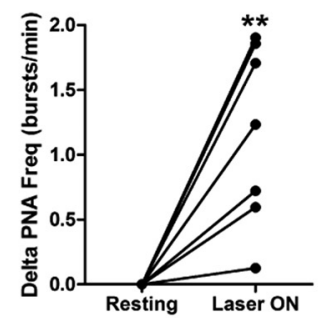

\section{F}

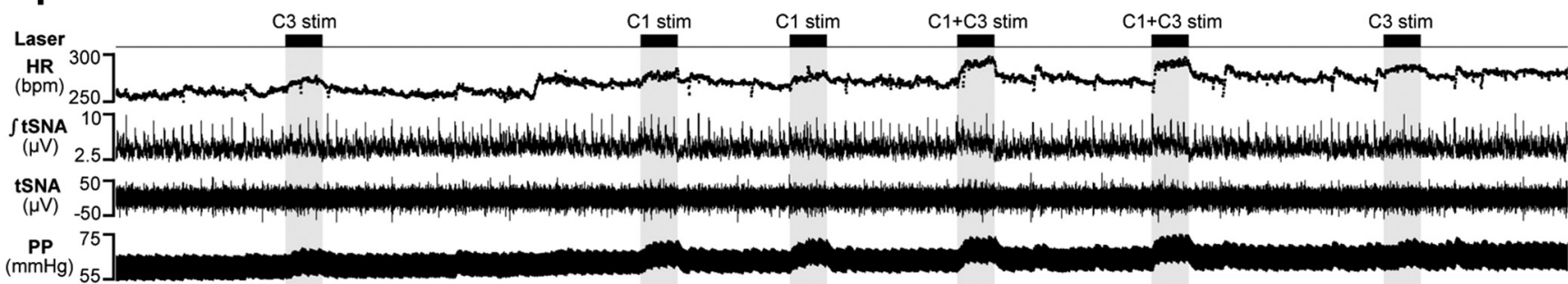

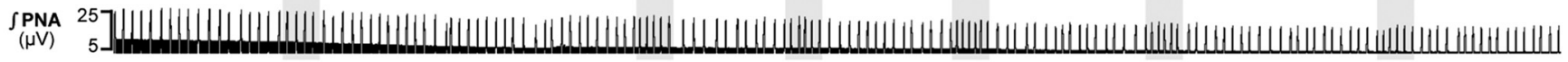

G

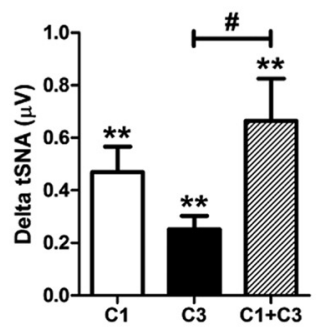

K
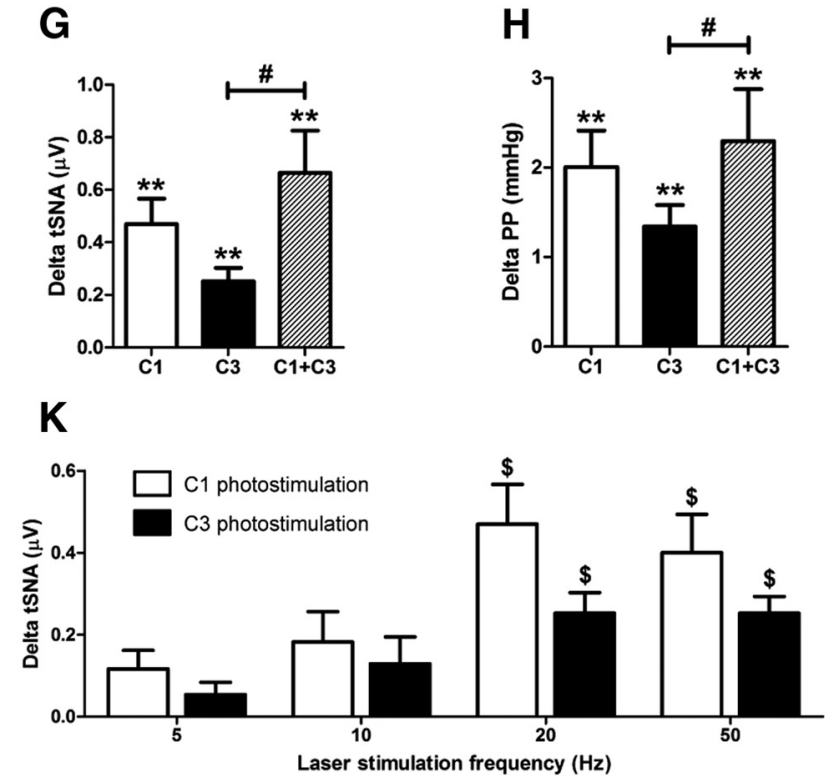

I

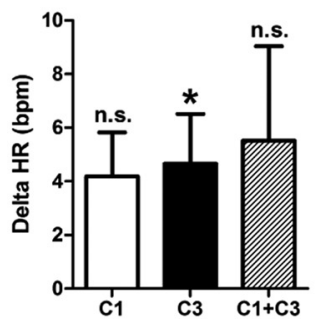

L

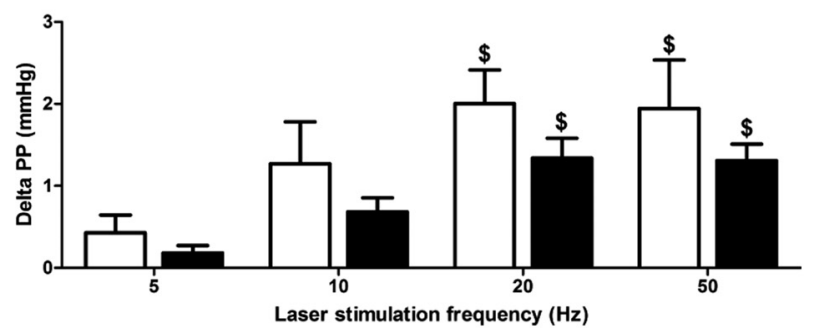

Figure 5. Optogenetic stimulation of C 3 and/or C1 neurons. A, Ten days after Lv-PRSX8-ChR2-YFP injection into the C 3 area in rats, the effects of optogenetic stimulation of C 3 neurons on HR, tSNA, PP, PNA, and vagus nerve activity (VNA; data not shown) were recorded in the WHBP. The tip of a $200-\mu \mathrm{m}$-diameter optical fiber was placed on the dorsal surface of the brainstem ( $40^{\circ}$ angle to the vertical, facing ventrocaudally), on the midline just above $(3$ neurons $(2 \mathrm{~mm}$ rostral to calamus scriptorius). Maximal photostimulation ( $20 \mathrm{~Hz}, 15 \mathrm{~ms}$ pulses, $600 \mathrm{pulses}, 10 \mathrm{~mW}$ light intensity) of (3 neurons (laser ON, shaded block) caused an increase in HR, baseline, are shown for tSNA $(\boldsymbol{B}), \mathrm{PP}(\boldsymbol{C}), \mathrm{HR}(\boldsymbol{D})$, and PNA $(\boldsymbol{E}) . \boldsymbol{F}$, Rate meter record showing a continuous 30 min recording of HR, 5 SNA, PP, and PNA with $\mathrm{C} 3, \mathrm{C} 1$, and simultaneous $\mathrm{C1}+\mathrm{C} 3$ maximal photostimulation. All C3 (black bars), C1 (white bars), and C1 + C3 (dashed bars) photostimulations significantly increased tSNA (G) and PP (H). C1 + C3 photostimulation produced a larger increase of both parameters than $\mathrm{C} 3$ photostimulation alone. I, Only C3 photostimulation significantly increased HR, although there was a tendency for an increase with $\mathrm{C} 1$ and $\mathrm{C} 1+\mathrm{C} 3$ photostimulations. J, C3, C1, and C1 + C3 photostimulations all increased PNA. Histograms showing the tSNA ( $\boldsymbol{K}$ ) and PP $(\boldsymbol{L})$ responses to $5,10,20$, and $50 \mathrm{~Hz} C 1$ (white bars) and C3 (black bars) photostimulations ( $15 \mathrm{~ms}$ pulses, 600 pulses, $10 \mathrm{~mW}$ light intensity). The 20 and $50 \mathrm{~Hz}$ photostimulations produced larger increases in both tSNA and PP compared with $5 \mathrm{~Hz}$ photostimulation. Maximal photostimulation effect was reached at $20 \mathrm{~Hz}$ for both $\mathrm{C} 1$ and $\mathrm{C} 3$ photostimulations as $50 \mathrm{~Hz}$ photostimulation did not cause any further increase. Data are mean \pm SEM. ${ }^{*} p<0.05$, within-subject comparison. ${ }^{* *} p<0.01$, within-subject comparison. ${ }^{* *} p<0.001$, within-subject comparison. ${ }^{*} p<0.05$, between-group comparison. ${ }^{\$} p<0.05$, compared with $5 \mathrm{~Hz}$ photostimulation. n.s., Not significant. 
the IML. C3 and C1 projections were found throughout the IML at all T1-T5 levels, with similar overall patterns of SPN innervation. Both C3 and C1 fibers crossed the spinal cord midline dorsal of the central canal and innervated the IML bilaterally, with denser $\mathrm{C} 1$ innervation on the ipsilateral side to $\mathrm{C} 1$ virus injection. All further analysis examined the IML ipsilateral to $\mathrm{C} 1$ viral injections.

$\mathrm{C} 1$ projections to ChAT-immunoreactive IML neurons were more dense than $\mathrm{C} 3$ projections (Fig. 7A-C). The $\mathrm{C} 1$ varicose axons tended to have dense clusters of terminals (Fig. 7D), whereas those from C3 neurons were less clustered with apparently greater distance between boutons (Fig. 7E). There was no obvious difference in the distribution of $\mathrm{C} 3$ and $\mathrm{C} 1$ varicose axons apposed to ChAT-immunoreactive IML neurons (Fig. $7 A$ ), although there were differences in their proportions (Figs. $7 B-E$ and $8 A-F$ ). In horizontal sections, whereas all ChATimmunoreactive IML clusters received both $\mathrm{C} 3$ and $\mathrm{C} 1$ axons, substantial variations in proportions of $\mathrm{C} 3 / \mathrm{C} 1$ axons were also present as shown in adjacent clusters of ChATimmunoreactive IML in Figure $7 \mathrm{~B}$. C1 neurons tended to innervate the more lateral ChAT-immunoreactive IML neurons (Fig. $7 A, C, D)$, whereas $\mathrm{C} 3$ neurons made frequent presumptive contacts with the more medial ChAT-immunoreactive IML neurons (Fig. 7C,E). These more medial ChATimmunoreactive IML neurons very rarely received $\mathrm{C} 1$ innervation. We also found that the more ventral horizontal sections receive predominantly $\mathrm{C} 1$ inputs with few, if any, C3 varicose axon, and inversely in the more dorsal horizontal sections. This was further represented in coronal sections, where C3 neurons predominated in the dorsal part of the IML, whereas $\mathrm{C} 1$ neurons predominated in the ventral part of the IML (Fig. $8 A-F$ ).

\section{Discussion}

This study provides the first defined function for catecholaminergic C3 neurons and shows that they form part of the circuitry activated in response to glucoprivation. These adrenergic neurons, one of only three groups in the CNS possessing this neurochemical phenotype, project widely throughout the CNS (Sevigny et al., 2012). Our detailed anatomical characterization divides the C3 neurons into four subgroups based on the spatial organization of cell bodies. These subgroups have exclusive projection patterns, the dorsal and lateral subgroups only projecting rostrally, the medial and median subgroups only projecting caudally. All C3 subgroups were strongly activated by glucoprivation, but not by hypotension. This selectivity of physiological responsiveness provides a contrast to the $\mathrm{Cl}$ neurons that are activated by both stimuli.

Using optogenetic stimulation in the WHBP of the rat, we demonstrate that C3 neurons elicit sympathoexcitation with an
B C
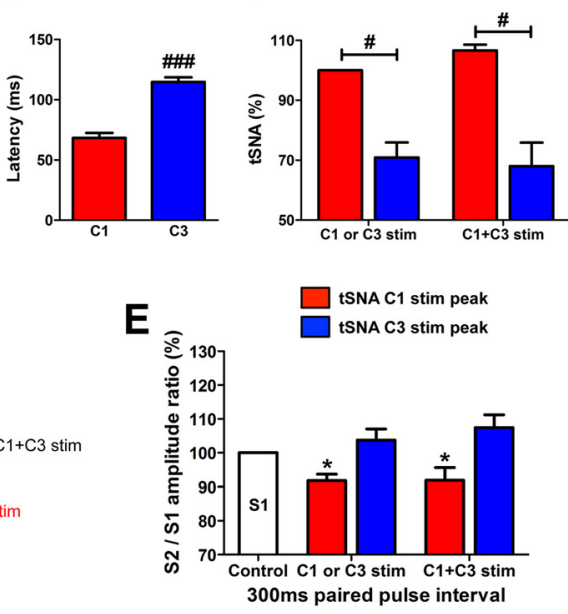

G

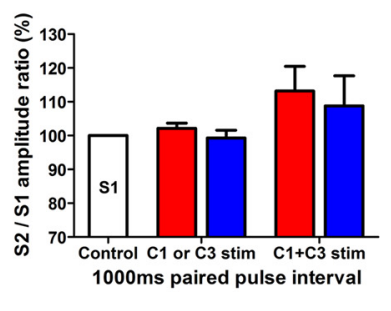

Figure 6. Low-frequency photostimulations reveal distinct patterns of SNA activation by C3 and C1 neurons. $\boldsymbol{A}$, Laser pulse triggered averaging of tSNA after $1 \mathrm{~Hz}$ photostimulations (15 ms pulses, 500 pulses, $10 \mathrm{~mW}$ light intensity) of C1 (red trace) or C3

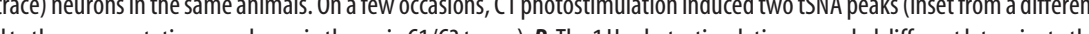
列

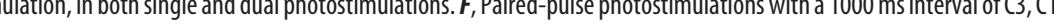
for all photostimulations. $\mathbf{G}$. There was no difference between the amplitudes of the first and second peaks of tSNA within-subject comparison. " $p<0.05$, between-group comparison. ${ }^{\# \#} p<0.001$, between-group comparison. S1, Photostimulation 1; S2, photostimulation 2.

increase in PP, HR, and respiratory frequency. The sympathoexcitatory effects during sustained photostimulation are similar to those obtained with $\mathrm{C} 1$ photostimulation, whereas dual photostimulation $(\mathrm{C} 1+\mathrm{C} 3)$ showed an additive effect. However, low-frequency photostimulations show that, compared with $\mathrm{C} 1$ neurons, C3 neurons induce delayed, less pronounced sympathoexcitation that is less sensitive to poststimulus depression. Using dual-viral labeling, we show that $\mathrm{C} 3$ and $\mathrm{C} 1$ projections toward SPNs of the thoracic IML share similarities, but with variations in the respective proportions of these projections to specific areas of the IML that might contribute to the different functional responses to stimulation of C3 versus $\mathrm{C} 1$ neurons.

Like the $\mathrm{C} 1$ and $\mathrm{C} 2$ adrenergic groups, C3 neurons express NPY, VGluT2, and VMAT2 (Stornetta, 2009). But whereas C1 and C2 neuronal groups are anatomically confined, C3 neurons are sparsely distributed over a long rostrocaudal and mediolateral area. An exception to this is the dorsal subgroup whose neurons occur in a compact distribution. The small number and sparse distribution of $\mathrm{C} 3$ neurons make it difficult to activate them with 

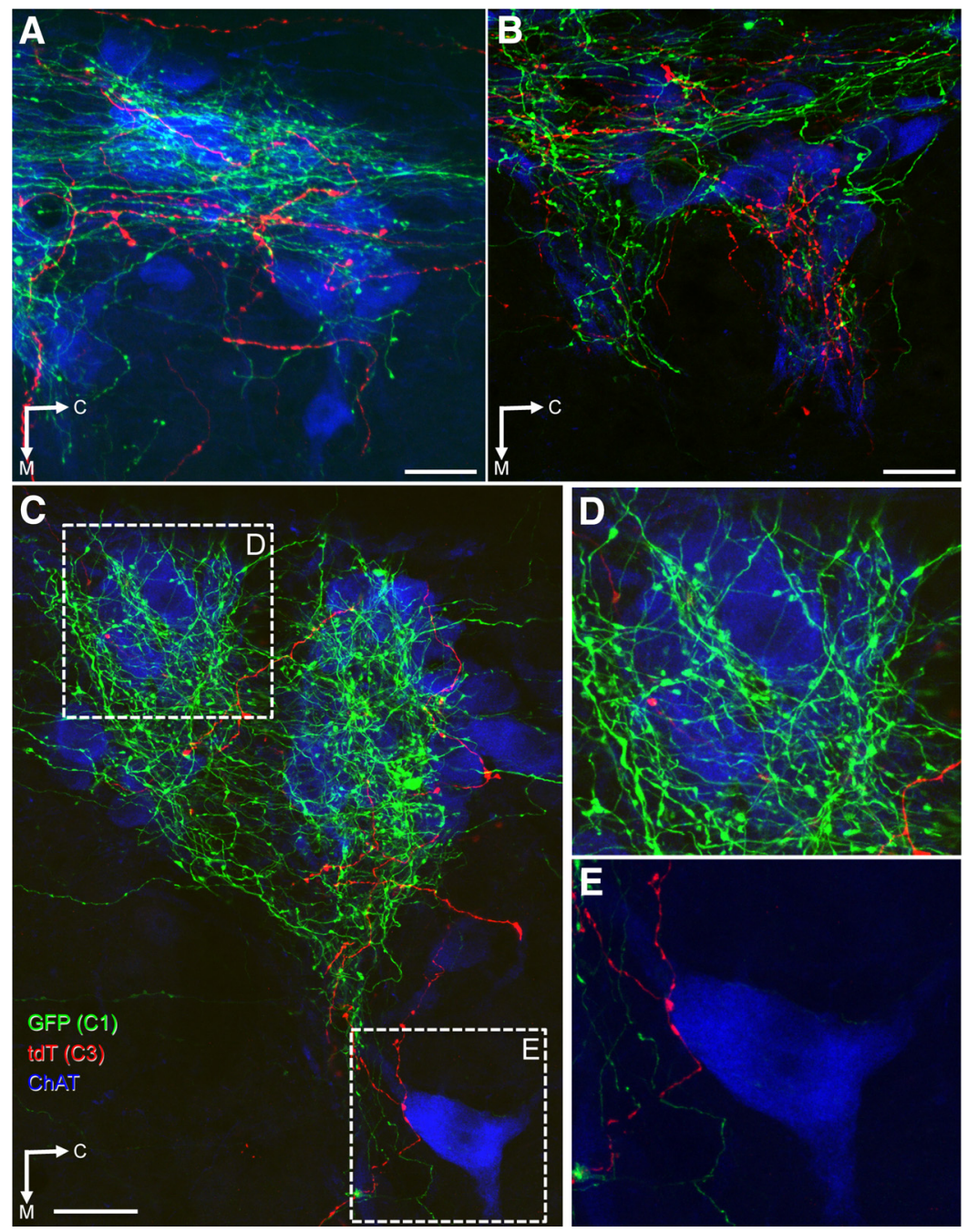

Figure 7. Axonal varicosities in the IML derived from C 3 and $C 1$ neurons. Confocal images of $40 \mu \mathrm{m}$ horizontal sections between T1-3 triple labeled for GFP (C1 projections, green), tdTomato (C3 projections, red), and ChAT (SPNs of the IML, blue) immunoreactivity. $\boldsymbol{A}$, Varicose axons from $C 3$ and $C 1$ neurons occur widely throughout the IML closely apposed to SPN. $\boldsymbol{B}$, Differences in the proportions of $\mathrm{C} 3$ and $\mathrm{C} 1$ varicose axons occur within different regions of the IML, as shown here in adjacent clusters of ChATimmunoreactive IML neurons (mostly GFP-immunoreactive $\mathrm{C}$ fibers in the rostral cluster, mostly tdTomato-immunoreactive $\mathrm{C} 3$ fibers in the caudal cluster). C, Lower-magnification photomicrograph showing the IML with extensive C1 projections and less C3 projections, which were typical. D, Enlargement of the corresponding dotted square in C showing cells in the lateral edge of the IML receiving extensive $C 1$ projections but very sparse $(3$ projections. $\boldsymbol{E}$, Enlargement of the corresponding dotted square in $\boldsymbol{C}$ showing a medial ChAT-immunoreactive neuron receiving $(3$ projection but no $\mathrm{C} 1$ projection. C, Caudal; M, medial; $\mathrm{tdT}$, tdTomato. Scale bars, $25 \mu \mathrm{m}$.

traditional chemical or electrical stimulation, and this probably accounts for the complete lack of knowledge about the function of these neurons (Stornetta, 2009). Using the unprecedented spatial and temporal resolution provided by viral-mediated expression of ChR2 (Boyden et al., 2005; Zhang et al., 2010; Yizhar et al., 2011), we revealed the sympathoexcitatory function of C3 neurons. Thus, our observations define another group of glutamatergic, sympathoexcitatory neurons that, like $\mathrm{C} 1$ neurons, express catecholamine-synthesizing enzymes.

$\mathrm{C} 1$ neurons are activated by multiple stimuli, including glucoprivation and hypotension. By contrast, the $\mathrm{C} 3$ neurons are robustly activated by glucoprivation and not by hypotension. This highlights a selective functional involvement of $\mathrm{C} 3$ neurons as opposed to the involvement of $\mathrm{C} 1$ neurons in a broad range of activities (Abbott et al., 2009b, 2012, 2013; Chen et al., 2010, 2012; Serrats et al., 2010; Marina et al., 2011; Ritter et al., 2011;
Guyenet et al., 2013). Also, it is unlikely that C3 neurons participate in the generation of basal sympathetic tone as their destruction, concomitantly with that of C1 neurons, does not affect resting SNA (Schreihofer et al., 2000).

The dense projections of $\mathrm{C} 3$ neurons throughout the neuraxis, including to the mediodorsal and paraventricular nuclei of the thalamus as well as many hypothalamic regions (Sevigny et al., 2012), suggest a widespread influence. We can now conclude that these thalamic and hypothalamic projections arise from $\mathrm{C} 3$ neurons in the dorsal and lateral subgroups. By contrast, the dense projections to the spinal cord arise from the median and medial subgroups. These conclusions are supported by the findings of Ritter et al. (2001) who showed that microinjection of the catecholaminergic-cell specific toxin anti-dopamine $\beta$-hydroxylase-saporin (anti-D $\beta \mathrm{H}$-sap) in the hypothalamus killed, among other catecholaminergic cell groups, the dorsal C3 neurons, whereas its injection in the spinal cord (T2-T4) killed the medial and median C3 neurons.

We used the PRSx8 promoter to drive transgene expression (Hwang et al., 2001). This promoter, a multimer of the phox2 binding domain, is widely used to target catecholaminergic cells (Card et al., 2006, 2011; Sevigny et al., 2008, 2012; Abbott et al., 2009b, 2012, 2013; Kanbar et al., 2010; Bruinstroop et al., 2012). However, there are also phox2-expressing cells that are not catecholaminergic (Kang et al., 2007; Card et al., 2010). Based upon the following information, we are confident the sympathetic responses to photostimulation of the $\mathrm{C} 3$ and $\mathrm{C} 1$ regions are from $\mathrm{C} 3$ and $\mathrm{C} 1$ neurons, respectively. The non-TH-immunoreactive neurons labeled from C3 injections were outside the boundaries of the C3 group, in the midline ventral to the $\mathrm{C} 3$ cells. Consequently, they are situated $>1.5 \mathrm{~mm}$ away from the tip of the optical probe, and we calculated that they would receive $<10 \%$ of the light power (Yizhar et al., 2011) (i.e., $3 \mathrm{~mW}$ in our experimental conditions), which we found was not sufficient to produce any alterations of the parameters recorded. Furthermore, all axon varicosities in the IML that were labeled from viral injections in the $\mathrm{C} 3$ region expressed $\mathrm{TH}$, indicating that the non- $\mathrm{TH}-$ immunoreactive neurons are not spinally projecting and unlikely to influence sympathetic activity within the millisecond timeframe observed in our recordings. Within the $\mathrm{C} 1$ region, we obtained similar levels of ChR2 expression in $\mathrm{C} 1$ neurons as in previously published $\mathrm{C} 1$ optogenetic studies (Abbott et al., 2009a, 2012). Similarly to C3 neurons, ChR2 expression in the RVLM was predominantly in TH-immunoreactive $\mathrm{C} 1$ cells, although some non-TH-immunoreactive neurons also expressed ChR2. These cells belong to the retrotrapezoid nucleus (Abbott et 
al., 2012) and do not alter SNA or blood pressure when optogenetically stimulated (Abbott et al., 2009a). After Lv-PRSx8GFP expression in the RVLM, the majority of GFP-labeled terminals in the IML also contained TH immunoreactivity, although there was not complete overlap. $\mathrm{TH}$ immunoreactivity in catecholaminergic neurons can vary greatly in intensity (Benno et al., 1982; Mezey, 1989), as commonly observed in $\mathrm{C} 1$ soma and axons (Phillips et al., 2001), and we conclude that immunoreactivity in terminals varies similarly so that, in some neurons, it is below the level of detectability.

We compared the C3-mediated sympathoexcitation with $\mathrm{C} 1$-mediated responses in the same animals. C1 optogenetic or pharmacogenetic stimulations induce large increases in SNA and blood pressure in vivo both in conscious and anesthetized animals (Abbott et al., 2009b; Chen et al., 2010; Kanbar et al., 2010). Here, we confirm the sympathoexcitatory function of $\mathrm{C} 1$ neurons in the in situ WHBP. The amplitude of the increase in sympathetic activity and PP induced by $40 \mathrm{~s}$ of $20 \mathrm{~Hz}$ maximal photostimulation of $\mathrm{C} 1 \mathrm{neu}-$ rons tended to be larger than that of $\mathrm{C} 3$ neurons stimulation. However, although $\mathrm{C} 1$ stimulation activates parasympathetic preganglionic neurons in the dorsal motor nucleus of the vagus (DePuy et al., 2013), we found no vagal activation after stimulation of either C3 or C1 neurons.

When performing low-frequency $1 \mathrm{~Hz}$ photostimulation, C1 neurons induced significantly larger tSNA activation than C3 neurons. As reported previously (Abbott et al., 2009b), paired-pulse stimulation of $\mathrm{C} 1$ neurons shows reduced second pulse-induced SNA amplitude due to a period of poststimulus SNA depression induced by the first pulse. Therefore, the effect of $\mathrm{Cl}$ activation on tSNA is reduced during highfrequency stimulation (e.g., $20 \mathrm{~Hz}$ ). Stimulation of C3 neurons induced less pronounced poststimulus depression in tSNA with no alteration in the size of the second tSNA response during paired pulse stimulation. This difference in poststimulus depression can account for the relatively larger tSNA activation induced by high-frequency maximal stimulation of C3 neurons compared with C1 neurons.

Dual C1 + C3 photostimulation, at maximal frequencies, produced additive increases in tSNA and PP compared with C3 photostimulation alone. This might be partially explained by the temporal difference in sympathoexcitation by these two groups as shown by the $1 \mathrm{~Hz}$ photostimulation. We also considered that this additive response might reflect a difference in class of postganglionic neurons activated by $\mathrm{C} 3$ and $\mathrm{C} 1$ neurons. SPNs are electrophysiologically heterogeneous; in particular, only some SPNs display prolonged after-hyperpolarizing currents (Yoshimura et al., 1986; Sah and McLachlan, 1995), which are thought to cause the poststimulus depression after $\mathrm{C} 1$ stimulation. Using dual-viral tracing experiments, we observed that the broad distribution of $\mathrm{C} 3$ and $\mathrm{C} 1$ neurons inputs to the IML is similar. However, there were relative differences in innervation within IML, with a relative predominance of varicose $\mathrm{C} 3$ axons in the dorsal and medial IML, and varicose $\mathrm{C} 1$ axons in the ventral and lateral IML. The thoracic IML contains $\sim 90 \%$ of all SPNs (Yip et al., 2000), and although the experimental data remain sparse, there is evidence for target-specific organization of subnuclei (Baron et al., 1985; Appel and Elde, 1988; Pyner and Coote, 1994; Gonsalvez et al., 2010). The most comprehensive of these studies indicates that adrenal medullary SPNs are situated in a ventral-lateral column, whereas those projecting to the superior cervical ganglion are in a dorsal-medial column; those projecting to the stellate ganglion are in between (Pyner and Coote, 1994). More medial SPNs, including those in the central canal, tend to project to visceral targets (Baron et al., 1985). CARTpositive neurons, which are putative vasomotor SPNs, are located medially in the IML and not in the central canal (Gonsalvez et al., 2010). Based upon this overall distribution, we conclude that these relative differences in projection patterns of C3 and C1 neurons, potentially to different classes of SPN, might contribute to the different tSNA responses after activation.

These anatomical and functional characteristics of C3 neurons, which are similar to but distinct from $\mathrm{C} 1$ neurons, suggest that this cell group has a unique role in cardiovasomotor regulation. Most C3 neurons are activated by glucoprivation, which, combined with their widespread projections, suggests a global role in regulation of autonomic, neuroendocrine, and behavioral functions associated with glucose homeostasis. Understanding the functional role of $\mathrm{C} 3$ neurons clearly requires further investigation, but we have definitively demonstrated their first known function, sympathoexcitation. 


\section{References}

Abbott SB, Stornetta RL, Fortuna MG, Depuy SD, West GH, Harris TE, Guyenet PG (2009a) Photostimulation of retrotrapezoid nucleus phox $2 \mathrm{~b}$-expressing neurons in vivo produces long-lasting activation of breathing in rats. J Neurosci 29:5806-5819. CrossRef Medline

Abbott SB, Stornetta RL, Socolovsky CS, West GH, Guyenet PG (2009b) Photostimulation of channelrhodopsin-2 expressing ventrolateral medullary neurons increases sympathetic nerve activity and blood pressure in rats. J Physiol 587:5613-5631. CrossRef Medline

Abbott SB, Coates MB, Stornetta RL, Guyenet PG (2013) Optogenetic stimulation of $\mathrm{cl}$ and retrotrapezoid nucleus neurons causes sleep state-dependent cardiorespiratory stimulation and arousal in rats. Hypertension 61:835-841. CrossRef Medline

Abbott SB, Kanbar R, Bochorishvili G, Coates MB, Stornetta RL, Guyenet PG (2012) C1 neurons excite locus coeruleus and A5 noradrenergic neurons along with sympathetic outflow in rats. J Physiol 590:2897-2915. CrossRef Medline

Appel NM, Elde RP (1988) The intermediolateral cell column of the thoracic spinal cord is comprised of target-specific subnuclei: evidence from retrograde transport studies and immunohistochemistry. J Neurosci 8:1767-1775. Medline

Baron R, Janig W, McLachlan EM (1985) The afferent and sympathetic components of the lumbar spinal outflow to the colon and pelvic organs in the cat: III. The colonic nerves, incorporating an analysis of all components of the lumbar prevertebral outflow. J Comp Neurol 238:158-168. CrossRef Medline

Benno RH, Tucker LW, Joh TH, Reis DJ (1982) Quantitative immunocytochemistry of tyrosine hydroxylase in rat brain: II. Variations in the amount of tyrosine hydroxylase among individual neurons of the locus coeruleus in relationship to neuronal morphology and topography. Brain Res 246:237-247. CrossRef Medline

Boyden ES, Zhang F, Bamberg E, Nagel G, Deisseroth K (2005) Millisecondtimescale, genetically targeted optical control of neural activity. Nat Neurosci 8:1263-1268. CrossRef Medline

Bruinstroop E, Cano G, Vanderhorst VG, Cavalcante JC, Wirth J, Sena-Esteves M, Saper CB (2012) Spinal projections of the A5, A6 (locus coeruleus), and A7 noradrenergic cell groups in rats. J Comp Neurol 520:1985-2001. CrossRef Medline

Bugarith K, Dinh TT, Li AJ, Speth RC, Ritter S (2005) Basomedial hypothalamic injections of neuropeptide $\mathrm{Y}$ conjugated to saporin selectively disrupt hypothalamic controls of food intake. Endocrinology 146:1179-1191. CrossRef Medline

Card JP, Sved JC, Craig B, Raizada M, Vazquez J, Sved AF (2006) Efferent projections of rat rostroventrolateral medulla $\mathrm{Cl}$ catecholamine neurons: implications for the central control of cardiovascular regulation. J Comp Neurol 499:840-859. CrossRef Medline

Card JP, Lois J, Sved AF (2010) Distribution and phenotype of Phox2acontaining neurons in the adult Sprague-Dawley rat. J Comp Neurol 518:2202-2220. CrossRef Medline

Card JP, Kobiler O, McCambridge J, Ebdlahad S, Shan Z, Raizada MK, Sved AF, Enquist LW (2011) Microdissection of neural networks by conditional reporter expression from a Brainbow herpesvirus. Proc Natl Acad Sci U S A 108:3377-3382. CrossRef Medline

Chen D, Bassi JK, Walther T, Thomas WG, Allen AM (2010) Expression of angiotensin type $1 \mathrm{~A}$ receptors in $\mathrm{C} 1$ neurons restores the sympathoexcitation to angiotensin in the rostral ventrolateral medulla of angiotensin type 1A knockout mice. Hypertension 56:143-150. CrossRef Medline

Chen D, Jancovski N, Bassi JK, Nguyen-Huu TP, Choong YT, Palma-Rigo K, Davern PJ, Gurley SB, Thomas WG, Head GA, Allen AM (2012) Angiotensin type $1 \mathrm{~A}$ receptors in $\mathrm{C} 1$ neurons of the rostral ventrolateral medulla modulate the pressor response to aversive stress. J Neurosci 32: 2051-2061. CrossRef Medline

DePuy SD, Stornetta RL, Bochorishvili G, Deisseroth K, Witten I, Coates M, Guyenet PG (2013) Glutamatergic neurotransmission between the C1 neurons and the parasympathetic preganglionic neurons of the dorsal motor nucleus of the vagus. J Neurosci 33:1486-1497. CrossRef Medline

Fenwick NM, Martin CL, Llewellyn-Smith IJ (2006) Immunoreactivity for cocaine- and amphetamine-regulated transcript in rat sympathetic preganglionic neurons projecting to sympathetic ganglia and the adrenal medulla. J Comp Neurol 495:422-433. CrossRef Medline

Gonsalvez DG, Kerman IA, McAllen RM, Anderson CR (2010) Chemical coding for cardiovascular sympathetic preganglionic neurons in rats. J Neurosci 30:11781-11791. CrossRef Medline

Guyenet PG, Stornetta RL, Bochorishvili G, Depuy SD, Burke PG, Abbott SB (2013) C1 neurons: the body's EMTs. Am J Physiol Regul Integr Comp Physiol 305:R187-R204. CrossRef Medline

Hwang DY, Carlezon WA Jr, Isacson O, Kim KS (2001) A high-efficiency synthetic promoter that drives transgene expression selectively in noradrenergic neurons. Hum Gene Ther 12:1731-1740. CrossRef Medline

Jeske I, McKenna KE (1992) Quantitative analysis of bulbospinal projections from the rostral ventrolateral medulla: contribution of C1adrenergic and nonadrenergic neurons. J Comp Neurol 324:1-13. CrossRef Medline

Kanbar R, Stornetta RL, Cash DR, Lewis SJ, Guyenet PG (2010) Photostimulation of Phox $2 \mathrm{~b}$ medullary neurons activates cardiorespiratory function in conscious rats. Am J Respir Crit Care Med 182:1184-1194. CrossRef Medline

Kang BJ, Chang DA, Mackay DD, West GH, Moreira TS, Takakura AC, Gwilt JM, Guyenet PG, Stornetta RL (2007) Central nervous system distribution of the transcription factor Phox $2 b$ in the adult rat. J Comp Neurol 503:627-641. CrossRef Medline

Li AJ, Wang Q, Dinh TT, Ritter S (2009) Simultaneous silencing of Npy and Dbh expression in hindbrain A1/C1 catecholamine cells suppresses glucoprivic feeding. J Neurosci 29:280-287. CrossRef Medline

Li AJ, Wang Q, Ritter S (2011) Participation of hindbrain AMP-activated protein kinase in glucoprivic feeding. Diabetes 60:436-442. CrossRef Medline

Llewellyn-Smith IJ, Dicarlo SE, Collins HL, Keast JR (2005) Enkephalinimmunoreactive interneurons extensively innervate sympathetic preganglionic neurons regulating the pelvic viscera. J Comp Neurol 488:278-289. CrossRef Medline

Llewellyn-Smith IJ, Kellett DO, Jordan D, Browning KN, Travagli RA (2012) Oxytocin-immunoreactive innervation of identified neurons in the rat dorsal vagal complex. Neurogastroenterol Motil 24:e136-e146. CrossRef Medline

Llewellyn-Smith IJ, Gnanamanickam GJ, Reimann F, Gribble FM, Trapp S (2013) Preproglucagon (PPG) neurons innervate neurochemically identified autonomic neurons in the mouse brainstem. Neuroscience 229: 130-143. CrossRef Medline

Marina N, Abdala AP, Korsak A, Simms AE, Allen AM, Paton JF, Gourine AV (2011) Control of sympathetic vasomotor tone by catecholaminergic $\mathrm{C} 1$ neurones of the rostral ventrolateral medulla oblongata. Cardiovasc Res 91:703-710. CrossRef Medline

McBryde FD, Abdala AP, Hendy EB, Pijacka W, Marvar P, Moraes DJ, Sobotka PA, Paton JF (2013) The carotid body as a putative therapeutic target for the treatment of neurogenic hypertension. Nat Commun 4:2395. CrossRef Medline

Mezey E (1989) Phenylethanolamine $N$-methyltransferase-containing neurons in the limbic system of the young rat. Proc Natl Acad Sci U S A 86:347-351. CrossRef Medline

Parker LM, Kumar NN, Lonergan T, McMullan S, Goodchild AK (2013) Distribution and neurochemical characterization of neurons in the rat ventrolateral medulla activated by glucoprivation. Brain Struct Funct. Advance online publication. Retrieved Oct. 8, 2013. doi: 10.1007/s00429013-0642-3. CrossRef Medline

Paton JF (1996) The ventral medullary respiratory network of the mature mouse studied in a working heart-brainstem preparation. J Physiol 493: 819-831. Medline

Paton JF, Abdala AP, Koizumi H, Smith JC, St-John WM (2006) Respiratory rhythm generation during gasping depends on persistent sodium current. Nat Neurosci 9:311-313. CrossRef Medline

Phillips JK, Goodchild AK, Dubey R, Sesiashvili E, Takeda M, Chalmers J, Pilowsky PM, Lipski J (2001) Differential expression of catecholamine biosynthetic enzymes in the rat ventrolateral medulla. J Comp Neurol 432:20-34. CrossRef Medline

Pyner S, Coote JH (1994) Evidence that sympathetic preganglionic neurones are arranged in target-specific columns in the thoracic spinal cord of the rat. J Comp Neurol 342:15-22. CrossRef Medline

Ritter S, Llewellyn-Smith I, Dinh TT (1998) Subgroups of hindbrain catecholamine neurons are selectively activated by 2-deoxy-D-glucose induced metabolic challenge. Brain Res 805:41-54. CrossRef Medline

Ritter S, Bugarith K, Dinh TT (2001) Immunotoxic destruction of distinct catecholamine subgroups produces selective impairment of glucoregula- 
tory responses and neuronal activation. J Comp Neurol 432:197-216. CrossRef Medline

Ritter S, Li AJ, Wang Q, Dinh TT (2011) Minireview. The value of looking backward: the essential role of the hindbrain in counterregulatory responses to glucose deficit. Endocrinology 152:4019-4032. CrossRef Medline

Sah P, McLachlan EM (1995) Membrane properties and synaptic potentials in rat sympathetic preganglionic neurons studied in horizontal spinal cord slices in vitro. J Auton Nerv Syst 53:1-15. CrossRef Medline

Schreihofer AM, Stornetta RL, Guyenet PG (2000) Regulation of sympathetic tone and arterial pressure by rostral ventrolateral medulla after depletion of $\mathrm{C} 1$ cells in rat. J Physiol 529:221-236. CrossRef Medline

Serrats J, Schiltz JC, García-Bueno B, van Rooijen N, Reyes TM, Sawchenko PE (2010) Dual roles for perivascular macrophages in immune-to-brain signaling. Neuron 65:94-106. CrossRef Medline

Sevigny CP, Bassi J, Teschemacher AG, Kim KS, Williams DA, Anderson CR, Allen AM (2008) C1 neurons in the rat rostral ventrolateral medulla differentially express vesicular monoamine transporter 2 in soma and axonal compartments. Eur J Neurosci 28:1536-1544. CrossRef Medline

Sevigny CP, Bassi J, Williams DA, Anderson CR, Thomas WG, Allen AM (2012) Efferent projections of C3 adrenergic neurons in the rat central nervous system. J Comp Neurol 520:2352-2368. CrossRef Medline

Simms AE, Paton JF, Pickering AE, Allen AM (2009) Amplified respiratorysympathetic coupling in the spontaneously hypertensive rat: does it contribute to hypertension? J Physiol 587:597-610. CrossRef Medline

Stornetta RL (2009) Neurochemistry of bulbospinal presympathetic neurons of the medulla oblongata. J Chem Neuroanat 38:222-230. CrossRef Medline

Stornetta RL, Schreihofer AM, Pelaez NM, Sevigny CP, Guyenet PG (2001)
Preproenkephalin mRNA is expressed by $\mathrm{C} 1$ and non-C1 barosensitive bulbospinal neurons in the rostral ventrolateral medulla of the rat. J Comp Neurol 435:111-126. CrossRef Medline

Stornetta RL, Sevigny CP, Guyenet PG (2002) Vesicular glutamate transporter DNPI/VGLUT2 mRNA is present in C1 and several other groups of brainstem catecholaminergic neurons. J Comp Neurol 444:191-206. CrossRef Medline

Tang F, Lane S, Korsak A, Paton JF, Gourine AV, Kasparov S, Teschemacher AG (2014) Lactate-mediated glia-neuronal signalling in the mammalian brain. Nat Commun 5:3284. CrossRef Medline

Verberne AJ, Sartor DM (2010) Rostroventrolateral medullary neurons modulate glucose homeostasis in the rat. Am J Physiol Endocrinol Metab 299:E802-E807. CrossRef Medline

Verberne AJ, Sabetghadam A, Korim WS (2014) Neural pathways that control the glucose counterregulatory response. Front Neurosci 8:38. CrossRef Medline

Yip JW, Yip YP, Nakajima K, Capriotti C (2000) Reelin controls position of autonomic neurons in the spinal cord. Proc Natl Acad Sci U S A 97:86128616. CrossRef Medline

Yizhar O, Fenno LE, Davidson TJ, Mogri M, Deisseroth K (2011) Optogenetics in neural systems. Neuron 71:9-34. CrossRef Medline

Yoshimura M, Polosa C, Nishi S (1986) Afterhyperpolarization mechanisms in cat sympathetic preganglionic neuron in vitro. J Neurophysiol 55:1234-1246. Medline

Zhang F, Gradinaru V, Adamantidis AR, Durand R, Airan RD, de Lecea L, Deisseroth K (2010) Optogenetic interrogation of neural circuits: technology for probing mammalian brain structures. Nat Protoc 5:439-456. CrossRef Medline 